\title{
Crop Rotation as a Better Sanitary Practice in Culture of Penaeus monodon (Fabricius, 1798)
}

\author{
N. Santhi ${ }^{1 *}$ and B. Deivasigamani ${ }^{2}$ \\ ${ }^{1}$ Department of Biotechnology, New Prince Shri Bhavani Arts and Science College, \\ Medavakkam, Chennai, India \\ ${ }^{2}$ CAS in Marine Biology, Annamalai University, Parangipettai-608502, India \\ *Corresponding author
}

\begin{tabular}{|c|c|}
\hline & A B S T R A C T \\
\hline $\begin{array}{l}\text { Ke y w o r d s } \\
\text { Penaeus monodon- } \\
\text { Crop Rotation, } \\
\text { Shrimp and tilopia }\end{array}$ & \multirow{3}{*}{$\begin{array}{l}\text { Crop rotation for disease control in shrimp culture is not yet widely recognized } \\
\text { although it is already an established practice in Agriculture, Many researchers } \\
\text { used this practice in various species like potato cyst-nematodes. The same practice } \\
\text { was followed by researchers. Information about crop rotation in aquaculture is } \\
\text { very less and it is yet to be explored. Crop rotation with shrimp and tilopia } \\
\text { indicate that the practice reduces diseases incidence in shrimp culture. In addition, } \\
\text { crop rotation may be effective in preventing not only bacterial diseases but viral } \\
\text { diseases as well to a certain extent as proven in agriculture. Crop rotation is a type } \\
\text { of "Sanitation" practice and is an integral part of plant health management. }\end{array}$} \\
\hline Article Info & \\
\hline $\begin{array}{l}\text { Accepted: } \\
\text { 24 January } 2017 \\
\text { Available Online: } \\
\text { 10 Februarv } 2017\end{array}$ & \\
\hline
\end{tabular}

\section{Introduction}

The farming of tiger shrimp (Penaeus monodon) contributes significantly to the economy of many countries in the Asia Pacific region. However, in recent years the shrimp farming ponds in many of these countries have declined due to persistent disease problem. Rather than white spot syndrome virus (WSSV), the luminous bacterium Vibrio harveyi has been associated with many of the disease out breaks.

Although $V$. harveyi has been considered a part of the normal microflora of shrimp and its environment, certain strains may be more pathogenic than others. When these pathogenic strains are plentiful, they can over whelm the immune system of shrimp, allowing diseases to occur. In naturally diseased $P$. monodon, $V$. harveyi invades the hepatopancreas tubules and causes extensive lesions even in the absence of other pathogen such as baculovirus and parasites (Jiravanichpaisal et al., 1994). V. harveyi produces proteases, phospholipases or hemolysins which may play important roles in the pathogenicity of $P$. monodon (Liu et al., 1996).

Continuous culture of shrimp over the past few years might have caused the increase of shrimp-pathogenic $V$. harveyi in the culture systems and related environments. Although many of the farms might have employed thorough pond preparation techniques, these 
bacteria would have passed over into succeeding cultures as they are protected by the biofilms. Bacterial biofilms are notably resistant to drying and disinfection (Paclibare et al., 1998). Karunasagar et al., (1996) found that $V$. harveyi can survive in sediments that are treated with high doses of disinfectants.

Because of the difficulty in reducing the concentration of pathogenic bacteria in shrimp ponds by conventional chemical disinfection, other effective means such as biological control should be explored. The additions into the environment of bacterial microorganisms that serve as antagonists of the target pathogens and the manipulation of the environment in such a way that beneficial microorganism are favored to proliferate. Examples of these approaches are the use of probiotics and crop rotation respectively.

Assuming probiotics can reduce pathogenic bacteria in shrimp ponds, the method may still not be cost-effective to small farms because high amounts of the costly probiotic products must be added to the ponds frequently. The second approach, i.e., crop rotation for disease control in shrimp cultures is not yet widely recognized although it is already an established practice in agriculture (Sieczka, 1989; Reeves et al., 1984; Kommendahl and Todd, 1991) and suggested for adoption in shrimp farming.

Crop rotation is a type of "sanitation" practice and is an integral part of plant health management. A sanitation practice should reduce the initial inoculum to a sufficiently low level so that the normal development of disease will not reach a high level to cause appreciable yield loss, provided unusual influx was avoided (Berger, 1977). Crop rotation in shrimp aquaculture is worth exploring and may prove feasible in view of the recent findings on the host specificity/preference of certain strains of $V$. harveyi. Liu et al., (1996) found differences in the pathogenicity of $V$. harveyi isolated from penaeid and non-penaeid sources.

In this present study, finfishes (Mugil cephalus and Chanos chanos) were cultured between crops of shrimps for crop rotation and the reduction in the incidence of shrimp diseases was observed.

\section{Materials and Methods}

The study was carried out in a shrimp farm situated on the Southern banks of Marakkanam (Lat. $12^{0} 12^{\prime} 30^{\prime}$ N; Long. $79^{0}$ 56' 27'E). This shrimp farm has two ponds each with water spread area (WSA) of 1.3 ha. The first crop was a fish culture experiment for 6 months followed by a shrimp culture experiment for $4 \frac{1}{2}$ months in one pond and the other pond was used as control and two shrimp culture experiments were carried out.

\section{Pond preparation}

\section{Soil culture}

Initially the $\mathrm{pH}$ of the pond soil was checked and was found to be between 6.0 and 6.5. Required quantity of lime $\left[\mathrm{Ca}(\mathrm{OH})_{2}\right]$ was applied to increase the $\mathrm{pH}$ to 7.2 and the bottom was tilted for oxygenating. The total amount of lime applied was $600 \mathrm{~kg}$ per pond. After a week of soil preparation, water from Marakkanam uppanar estuary was pumped in with the help of a $10 \mathrm{HP}$ (Kirloskar) pump.

\section{Water culture}

The water was pumped in directly from the source and filtered in an $80 \mu$ mesh filter bag. Initial fertilization was done using cow dung at the rate of $100 \mathrm{~kg}$ per hectare and inorganic fertilizers in the ratio of 10:2 (N:P) for fish culture. For shrimp culture, fertilizers were not applied but dosages of dolomite were 
added regularly throughout the culture period. Within a period of one week, plankton development could be observed, mainly represented by diatoms.

\section{Stocking}

The fish seeds of 5 to $7 \mathrm{~g}$ individual weight were collected from the wild and required numbers were sorted out and stocked in the ponds at the rate of 7000 and 8000 numbers of Mugil cephalus and Chanos chanos respectively in 1.3 ha. For shrimp culture, the seeds were purchased from a reputed fish hatchery (MMR Hatcheries, Marakkanam) and were stocked at a density of 7.7 shrimps / $\mathrm{m}^{2}$. In the control pond, the shrimps were stocked at the same density.

\section{Feeding}

Initial feeding was done using rice bran and groundnut oil cake and during the later stages, a commercial fish feed (Higashimaru feeds India Ltd) was used. The feed was given at 5 $\%$ of the body weight regularly. During the early stages, bottom algae and animal cules (Lab lab) were allowed to grow, as they serve as an important natural food to the milk fishes.

For shrimp culture, feeding was done using CP feed (Chennai). The feeding schedule was based on the feed chart provided by the manufacturing company. Blind feeding was done for the first 30 days. Later, the feeding was adjusted based on the check tray observation and sampling. Four check trays / pond were installed.

The daily feed ration was divided for 4 feeding, 25\% for morning (6.00 AM), 20\% for noon (12.00 Noon), 30\% for evening (6.00 PM) and 25\% for night (1.00 AM) feeding respectively. The feed was broadcast from the dyke during the initial phase and boat feeding followed during the later stages. The same practice was followed in the control pond also (Plates 2 and 3).

\section{Sampling}

Random sampling was done every fortnight for fish culture and once in 10 days for shrimp culture, during early hours of the day with a cast net. Five hauls were made in the pond.

The animals caught per haul and their individual weights were recorded. Healthiness, survival rate, average body weight $(\mathrm{ABW})$ and average daily growth (ADG) of the animal was estimated through the samples. The diameter of the cast net used for sampling was $3.3 \mathrm{mts}$. The area of the net was calculated with $60 \%$ efficiency of coverage at the bottom.

\section{Water exchange}

Water exchanges were done at the rate of $10-$ $15 \mathrm{~cm} /$ day on a weekly once basis for both the cultures and the control experiments.

\section{Water quality assessment}

Water quality analysis was done following standard methods mentioned.

\section{Microbial analysis}

In this study, sediment and water samples from fish, shrimps and the control experiments separately, were analyzed. Water and sediment samples were taken from the pond with the help of presterilized bottles and polythene bags.

The collected samples were transferred to the laboratory immediately and analyzed within an hour of collection to avoid possible contaminations. Five tube three dilution MPN (Most Probable Number) methods were followed for all the samples. For water sample, $10 \mathrm{ml}$ of unfiltered water was 
transferred to double strength Alkaline Peptone Water (APW). Then, $1 \mathrm{ml}$ and $0.1 \mathrm{ml}$ aliquots were transferred to a single strength APW. For analysis of sediment samples, approximately $10 \mathrm{gm}$ of sediment was added to $90 \mathrm{ml}$ of water blank and from the water blank $10 \mathrm{ml}, 1 \mathrm{ml}$ and $0.1 \mathrm{ml}$ aliquots were transferred to double strength and single strength APW respectively (Five dilution in five tube method) (U.S. Food and Drug Administration (FDA) bacteriological manual, 1984).

\section{Results and Discussion}

\section{Water quality assessment}

\section{Temperature}

Temperature was found to vary between 28.5 and $32.4^{\circ} \mathrm{C}$ and 24.3 and $28.1^{\circ} \mathrm{C}$ during fish and shrimp culture respectively. It ranged between 29.6 and $32.9^{\circ} \mathrm{C}$ and 25.6 and $29.9^{\circ} \mathrm{C}$ in control ponds (experiment 1 and 2) respectively (Figs. 1, 2, 3 and 4).

\section{Salinity}

During fish culture, salinity ranged from 26 to $42 \mathrm{ppt}$. the same ranged between 10 to $19 \mathrm{ppt}$ during the shrimp culture experiment. In the control experiments 1 and 2, it ranged from 28.7 to $44 \mathrm{ppt}$ and 12 to $21 \mathrm{ppt}$ respectively (Figs. 5, 6, 7 and 8).

\section{Transparency}

Transparency reduced from 95 to $55 \mathrm{~cm}$ during fish culture experiment and 95 to 58 $\mathrm{cm}$ during shrimp culture experiment. In control experiment 1 , it reduced from 90 to 49 $\mathrm{cm}$ and in control experiment 2, it reduced from 85 to $55 \mathrm{~cm}$ (Figs. 9, 10, 11 and 12).

\section{Dissolved oxygen}

The D.O content ranged from $4.1-6.2 \mathrm{mg} / \mathrm{l}$ during fish culture and $4.2-6.1 \mathrm{mg} / \mathrm{l}$ during shrimp culture. In the control experiments, the values were from 4.2 to 5.9 and from 4.6 to 6.1 in 1 and 2 respectively (Figs. 13, 14, 15 and 16).

\section{pH}

The $\mathrm{pH}$ values ranged between 7.2 and 8.1 during fish culture and 7.1 and 8.6 during shrimp culture. In the control experiment 1, the values varied between 7.6 and 8.4 and in the control experiment 2 , it ranged between 7.5 and 8.3 (Figs. 17, 18, 19 and 20).

\section{Ammonia}

The values of ammonia during fish culture increased from 0.30 to $1.18 \mathrm{ppm}$. During shrimp culture, the values increased from 0.52 to $1.03 \mathrm{ppm}$. The values ranged from 0.61 to $1.13 \mathrm{ppm}$ and from 0.70 to $0.99 \mathrm{ppm}$ in the control experiments 1 and 2 respectively (Figs. 21, 22, 23 and 24).

\section{Nitrite}

During fish culture, the values of nitrite ranged from 0.0022 to $0.0170 \mathrm{ppm}$ and the values were from 0.0024 to $0.0119 \mathrm{ppm}$ during shrimp culture. In the control experiments 1 and 2, the values were between 0.0026 and $0.0123 \mathrm{ppm}$ and from 0.0034 to $0.0131 \mathrm{ppm}$ respectively (Figs.25, 26, 27 and 28).

\section{Nitrate}

Nitrate values ranged between 0.0035 and $0.0157 \mathrm{ppm}$ during fish culture and 0.0035 and $0.0125 \mathrm{ppm}$ during shrimp culture. The values were from 0.0039 to $0.0130 \mathrm{ppm}$ and from 0.0029 to $0.0136 \mathrm{ppm}$ in control experiments 1 and 2 respectively (Figs. 29, 20, 21 and 32). 


\section{Phosphate}

The values of phosphate ranged from 0.0017 to $0.0116 \mathrm{ppm}$ during fish culture and the same fluctuated between 0.0030 and 0.0098 ppm during shrimp culture. In the control experiment 1 , the values ranged from 0.0028 to $0.0097 \mathrm{ppm}$ and in the control experiment 2 , the values were between 0.0031 and 0.0102 ppm (Figs. 33, 34, 35 and 36).

\section{Silicate}

Silicate ranged between 0.0042 and 0.0128 ppm during fish culture and 0.0065 and $0.0130 \mathrm{ppm}$ during shrimp culture. The values were from 0.0061 to $0.0134 \mathrm{ppm}$ and 0.0059 to $0.0129 \mathrm{ppm}$ in the control experiments 1 and 2 (Figs. 37, 38, 39 and 40).

\section{Microbial analysis}

The results from the microbial analysis showed that the population of sucrose positive bacteria both in the water and sediment samples increased during the fish culture experiment $\left(3.3 \times 10^{2}-1.1 \times 10^{3} \mathrm{MPN} / 100 \mathrm{ml}\right.$ and $3.8 \times 10^{2}-1.4 \times 10^{3} \mathrm{MPN} / 100 \mathrm{mg}$ in water and sediment respectively). The sucrose negative bacterial population was more or less stable throughout the culture period $\left(2.6 \times 10^{2}\right.$ $-4.6 \times 10^{2} \mathrm{MPN} / 100 \mathrm{ml}$ and $5.6 \times 10^{2}-8.4 \times 10^{2}$ MPN/100mg in water and sediment respectively) (Table 1). During the shrimp culture experiment, there was a gradual reduction in the population of sucrose positive bacteria $\left(4.5 \times 10^{2}-3 \times 10^{2} \mathrm{MPN} / 100 \mathrm{ml}\right.$ and $6.2 \times 10^{2}-3 \times 10^{2} \mathrm{MPN} / 100 \mathrm{mg}$ in water and sediment samples respectively) and an increase in the population of sucrose negative bacteria $\left(3.3 \times 10^{2}-1.1 \times 10^{3} \mathrm{MPN} / 100 \mathrm{ml}\right.$ and $4.6 \times 10^{2}-1.3 \times 10^{3}$ in water and sediment samples respectively) (Table 2). In the control experiment 1, the population of sucrose positive bacteria in the water sample was found to be reducing from $3.2 \times 10^{2}$ to $2.3 \times 10^{2}$ MPN/100ml, whereas the population of sucrose negative strain increased from $4.3 \times 10^{2}$ to $1.4 \times 10^{3} \mathrm{MPN} / 100 \mathrm{ml}$. In sediment samples, the sucrose positive bacterial populations ranged between $2.4 \times 10^{2}$ and $3.4 \times 10^{2} \mathrm{MPN} / 100 \mathrm{gm}$. The sucrose negative populations increased from $4.8 \times 10^{2}$ to $1.5 \times 10^{3}$ MPN/100gm (Table 3). In the control experiment 2, the population of sucrose positive bacteria in the water sample was found to be reducing from $3.4 \times 10^{2}$ to $2.4 \times 10^{2}$ MPN $/ 100 \mathrm{ml}$, whereas the population of sucrose negative strain increased from $4.8 \times 10^{2}$ to $8.6 \times 10^{2} \mathrm{MPN} / 100 \mathrm{ml}$. In sediment samples, the sucrose positive bacterial populations ranged between $2.6 \times 10^{2}$ and $3.6 \times 10^{2} \mathrm{MPN} / 100 \mathrm{gm}$. The sucrose negative populations increased from $6.1 \times 10^{2}$ to $1.6 \times 10^{3}$ MPN/100gm. The control experiment 2 was terminated on $96^{\text {th }}$ DOC due to high mortalities due to Vibriosis (Table 4).

\section{Performance of the cultured organisms}

In the crop rotation experiment, the total production of fishes (Mugil cephalus and Chanos chanos) was $1308.6 \mathrm{~kg}$ in 180 days. The ABW of Mugil cephalus and Chanos chanos was $108 \mathrm{~g}$ and $153 \mathrm{~g}$ respectively. In shrimp culture in the same pond after fish culture, the production of shrimp was 2557.5 $\mathrm{kg}$ with a survival of $75 \%$ in 130 days with an $\mathrm{ABW}$ and $\mathrm{ADG}$ of $34.1 \mathrm{~g}$ and $0.26 \mathrm{~g}$ respectively.

In the control pond (continuous shrimp culture), shrimp production during the first and second crops was 1696.5 and $1043.1 \mathrm{~kg}$ respectively with a corresponding survival rate of 56 and $57 \%$. However, in the control pond, during the second crop, culture could not be extended beyond 90 days, due to bacterial problems (Table 5, 6, 7, 8 and 9). 
Table.1 Vibrio population in fish culture pond

\begin{tabular}{|c|c|c|c|c|}
\hline \multirow{2}{*}{$\begin{array}{l}\text { Days Of } \\
\text { Culture }\end{array}$} & \multicolumn{2}{|c|}{ Water sample } & \multicolumn{2}{|c|}{ Sediment sample } \\
\hline & $\begin{array}{l}\text { Sucrose positive } \\
\text { MPN/100 ml }\end{array}$ & $\begin{array}{l}\text { Sucrose negative } \\
\text { MPN/100 ml }\end{array}$ & $\begin{array}{c}\text { Sucrose positive } \\
\text { MPN/100g }\end{array}$ & $\begin{array}{c}\text { Sucrose negative } \\
\text { MPN/100g }\end{array}$ \\
\hline 10 & $3.3 \times 10^{2}$ & $2.6 \times 10^{2}$ & $3.8 \times 10^{2}$ & $5.8 \times 10^{2}$ \\
\hline 20 & $3.3 \times 10^{2}$ & $3.2 \times 10^{2}$ & $3.9 \times 10^{2}$ & $7.6 \times 10^{2}$ \\
\hline 30 & $3.9 \times 10^{2}$ & $3.2 \times 10^{2}$ & $4.5 \times 10^{2}$ & $6.4 \times 10^{2}$ \\
\hline 40 & $4.0 \times 10^{2}$ & $4.4 \times 10^{2}$ & $3.8 \times 10^{2}$ & $8.4 \times 10^{2}$ \\
\hline 50 & $4.7 \times 10^{2}$ & $3.1 \times 10^{2}$ & $4.4 \times 10^{2}$ & $7.0 \times 10^{2}$ \\
\hline 60 & $5.4 \times 10^{2}$ & $2.6 \times 10^{2}$ & $4.7 \times 10^{2}$ & $4.9 \times 10^{2}$ \\
\hline 70 & $5.4 \times 10^{2}$ & $3.0 \times 10^{2}$ & $5.9 \times 10^{2}$ & $6.2 \times 10^{2}$ \\
\hline 80 & $6.2 \times 10^{2}$ & $4.6 \times 10^{2}$ & $6.2 \times 10^{2}$ & $6.9 \times 10^{2}$ \\
\hline 90 & $6.4 \times 10^{2}$ & $4.2 \times 10^{2}$ & $6.9 \times 10^{2}$ & $5.6 \times 10^{2}$ \\
\hline 100 & $5.4 \times 10^{2}$ & $3.2 \times 10^{2}$ & $7.6 \times 10^{2}$ & $6.4 \times 10^{2}$ \\
\hline 110 & $7.6 \times 10^{2}$ & $4.4 \times 10^{2}$ & $8.4 \times 10^{2}$ & $7.2 \times 10^{2}$ \\
\hline 120 & $7.6 \times 10^{2}$ & $3.8 \times 10^{2}$ & $8.4 \times 10^{2}$ & $6.9 \times 10^{2}$ \\
\hline 130 & $8.4 \times 10^{2}$ & $3.3 \times 10^{2}$ & $9.5 \times 10^{2}$ & $5.9 \times 10^{2}$ \\
\hline 140 & $8.4 \times 10^{2}$ & $3.9 \times 10^{2}$ & $1.1 \times 10^{3}$ & $6.4 \times 10^{2}$ \\
\hline 150 & $9.5 \times 10^{2}$ & $3.9 \times 10^{2}$ & $1.3 \times 10^{3}$ & $7.0 \times 10^{2}$ \\
\hline 160 & $1.1 \times 10^{3}$ & $4.4 \times 10^{2}$ & $1.4 \times 10^{3}$ & $6.4 \times 10^{2}$ \\
\hline 170 & $1.1 \times 10^{3}$ & $3.6 \times 10^{2}$ & $1.4 \times 10^{3}$ & $7.6 \times 10^{2}$ \\
\hline
\end{tabular}

Table.2 Vibrio population in Shrimp culture pond

\begin{tabular}{|c|c|c|c|c|}
\hline $\begin{array}{c}\text { Days Of } \\
\text { Culture }\end{array}$ & \multicolumn{2}{|c|}{ Water sample } & \multicolumn{2}{c|}{ Sediment sample } \\
\cline { 2 - 5 } & $\begin{array}{c}\text { Sucrose positive } \\
\text { MPN/100 } \mathbf{~ m l}\end{array}$ & $\begin{array}{c}\text { Sucrose negative } \\
\text { MPN/100 ml }\end{array}$ & $\begin{array}{c}\text { Sucrose positive } \\
\text { MPN/100g }\end{array}$ & $\begin{array}{c}\text { Sucrose negative } \\
\text { MPN/100g }\end{array}$ \\
\hline 10 & $4.5 \times 10^{2}$ & $3.3 \times 10^{2}$ & $4.5 \times 10^{2}$ & $4.5 \times 10^{2}$ \\
\hline 20 & $6.2 \times 10^{2}$ & $4.6 \times 10^{2}$ & $6.2 \times 10^{2}$ & $4.8 \times 10^{2}$ \\
\hline 30 & $5.8 \times 10^{2}$ & $4.3 \times 10^{2}$ & $5.8 \times 10^{2}$ & $5.8 \times 10^{2}$ \\
\hline 40 & $5.4 \times 10^{2}$ & $5.8 \times 10^{2}$ & $5.4 \times 10^{2}$ & $4.6 \times 10^{2}$ \\
\hline 50 & $5.2 \times 10^{2}$ & $6.4 \times 10^{2}$ & $5.2 \times 10^{2}$ & $7.0 \times 10^{2}$ \\
\hline 60 & $4.8 \times 10^{2}$ & $7.2 \times 10^{2}$ & $4.8 \times 10^{2}$ & $8.1 \times 10^{2}$ \\
\hline 70 & $4.7 \times 10^{2}$ & $7.6 \times 10^{2}$ & $4.7 \times 10^{2}$ & $8.1 \times 10^{2}$ \\
\hline 80 & $4.5 \times 10^{2}$ & $7.6 \times 10^{2}$ & $4.5 \times 10^{2}$ & $8.4 \times 10^{2}$ \\
\hline 90 & $3.9 \times 10^{2}$ & $7.6 \times 10^{2}$ & $3.9 \times 10^{2}$ & $9.5 \times 10^{2}$ \\
\hline 100 & $4.2 \times 10^{2}$ & $8.1 \times 10^{2}$ & $4.2 \times 10^{2}$ & $1.1 \times 10^{3}$ \\
\hline 110 & $3.6 \times 10^{2}$ & $8.4 \times 10^{2}$ & $3.6 \times 10^{2}$ & $1.1 \times 10^{3}$ \\
\hline 120 & $3.6 \times 10^{2}$ & $9.5 \times 10^{2}$ & $3.6 \times 10^{2}$ & $1.2 \times 10^{3}$ \\
\hline 130 & $3.0 \times 10^{2}$ & $1.1 \times 10^{3}$ & $3.0 \times 10^{2}$ & $1.3 \times 10^{3}$ \\
\hline
\end{tabular}


Table.3 Vibrio population in control experiment 1

\begin{tabular}{|c|c|c|c|c|}
\hline \multirow[b]{2}{*}{$\begin{array}{l}\text { Days } \\
\text { Of } \\
\text { Culture }\end{array}$} & \multicolumn{2}{|c|}{ Water sample } & \multicolumn{2}{|c|}{ Sediment sample } \\
\hline & $\begin{array}{c}\text { Sucrose } \\
\text { positive } \\
\text { MPN/100 ml }\end{array}$ & $\begin{array}{c}\text { Sucrose } \\
\text { negative } \\
\text { MPN/100 ml }\end{array}$ & $\begin{array}{c}\text { Sucrose } \\
\text { positive } \\
\text { MPN/100g }\end{array}$ & $\begin{array}{c}\text { Sucrose negative } \\
\text { MPN/100g }\end{array}$ \\
\hline 10 & $3.2 \times 10^{2}$ & $4.3 \times 10^{2}$ & $3 \times 10^{2}$ & $4.8 \times 10^{2}$ \\
\hline 20 & $3 \times 10^{2}$ & $5.6 \times 10^{2}$ & $3 \times 10^{2}$ & $5.1 \times 10^{2}$ \\
\hline 30 & $3 \times 10^{2}$ & $5.3 \times 10^{2}$ & $3 \times 10^{2}$ & $6.2 \times 10^{2}$ \\
\hline 40 & $2.9 \times 10^{2}$ & $5.8 \times 10^{2}$ & $3.4 \times 10^{2}$ & $5.9 \times 10^{2}$ \\
\hline 50 & $2.8 \times 10^{2}$ & $6.7 \times 10^{2}$ & $3.4 \times 10^{2}$ & $6.8 \times 10^{2}$ \\
\hline 60 & $2.5 \times 10^{2}$ & $7.6 \times 10^{2}$ & $2.8 \times 10^{2}$ & $7.9 \times 10^{2}$ \\
\hline 70 & $2.5 \times 10^{2}$ & $7.8 \times 10^{2}$ & $2.6 \times 10^{2}$ & $8.4 \times 10^{2}$ \\
\hline 80 & $2.7 \times 10^{2}$ & $8.4 \times 10^{2}$ & $3 \times 10^{2}$ & $9.6 \times 10^{2}$ \\
\hline 90 & $2.4 \times 10^{2}$ & $8.4 \times 10^{2}$ & $2.9 \times 10^{2}$ & $1.1 \times 10^{3}$ \\
\hline 100 & $2.4 \times 10^{2}$ & $8.8 \times 10^{2}$ & $2.5 \times 10^{2}$ & $1.3 \times 10^{3}$ \\
\hline 110 & $2.3 \times 10^{2}$ & $9.6 \times 10^{2}$ & $2.5 \times 10^{2}$ & $1.4 \times 10^{3}$ \\
\hline 120 & $2.5 \times 10^{2}$ & $1.2 \times 10^{3}$ & $2.4 \times 10^{2}$ & $1.3 \times 10^{3}$ \\
\hline 130 & $2.3 \times 10^{2}$ & $1.4 \times 10^{3}$ & $2.6 \times 10^{2}$ & $1.5 \times 10^{3}$ \\
\hline
\end{tabular}

Table.4 Vibrio population in control experiment 2

\begin{tabular}{|c|c|c|c|c|}
\hline \multirow{2}{*}{$\begin{array}{c}\text { Days } \\
\text { of } \\
\text { Culture }\end{array}$} & \multicolumn{2}{|c|}{ Water sample } & \multicolumn{2}{|c|}{ Sediment sample } \\
\hline & $\begin{array}{c}\text { Sucrose } \\
\text { positive } \\
\text { MPN/100 ml }\end{array}$ & $\begin{array}{c}\text { Sucrose } \\
\text { negative } \\
\text { MPN/100 ml }\end{array}$ & $\begin{array}{c}\text { Sucrose } \\
\text { positive } \\
\text { MPN/100g }\end{array}$ & $\begin{array}{l}\text { Sucrose negative } \\
\text { MPN/100g }\end{array}$ \\
\hline 10 & $3.4 \times 10^{2}$ & $4.8 \times 10^{2}$ & $3.6 \times 10^{2}$ & $6.1 \times 10^{2}$ \\
\hline 20 & $3.8 \times 10^{2}$ & $5.4 \times 10^{2}$ & $3.6 \times 10^{2}$ & $6.8 \times 10^{2}$ \\
\hline 30 & $3.6 \times 10^{2}$ & $5.8 \times 10^{2}$ & $3.8 \times 10^{2}$ & $7.3 \times 10^{2}$ \\
\hline 40 & $2.8 \times 10^{2}$ & $6.4 \times 10^{2}$ & $3.6 \times 10^{2}$ & $8.6 \times 10^{2}$ \\
\hline 50 & $2.9 \times 10^{2}$ & $6.9 \times 10^{2}$ & $3.4 \times 10^{2}$ & $9.7 \times 10^{2}$ \\
\hline 60 & $2.7 \times 10^{2}$ & $7.6 \times 10^{2}$ & $2.9 \times 10^{2}$ & $1.4 \times 10^{3}$ \\
\hline 70 & $2.7 \times 10^{2}$ & $8.2 \times 10^{2}$ & $2.6 \times 10^{2}$ & $1.4 \times 10^{3}$ \\
\hline 80 & $2.7 \times 10^{2}$ & $8.6 \times 10^{2}$ & $2.8 \times 10^{2}$ & $1.6 \times 10^{3}$ \\
\hline 90 & $2.4 \times 10^{2}$ & $8.6 \times 10^{2}$ & $2.7 \times 10^{2}$ & $1.6 \times 10^{3}$ \\
\hline
\end{tabular}


Table.5 Growth and Survival of Mullets (Mugil cephalus)

\begin{tabular}{|c|c|c|c|c|}
\hline $\begin{array}{c}\text { Days of } \\
\text { Culture }\end{array}$ & $\begin{array}{c}\text { Survival } \\
\text { \% }\end{array}$ & ABW (gm) & ADG (gm) & $\begin{array}{c}\text { Biomass } \\
\text { (kg) }\end{array}$ \\
\hline 15 & 85 & 15 & 1.0 & 89.25 \\
\hline 30 & 83 & 22 & 0.73 & 127.82 \\
\hline 45 & 81 & 26 & 0.57 & 147.42 \\
\hline 60 & 80 & 31 & 0.51 & 173.60 \\
\hline 75 & 79 & 40 & 0.53 & 221.20 \\
\hline 90 & 77 & 48 & 0.53 & 258.72 \\
\hline 105 & 75 & 54 & 0.51 & 283.50 \\
\hline 120 & 73 & 68 & 0.56 & 347.48 \\
\hline 135 & 70 & 76 & 0.56 & 372.40 \\
\hline 150 & 68 & 86 & 0.57 & 409.36 \\
\hline 165 & 65 & 95 & 0.57 & 432.25 \\
\hline 180 & 63 & 108 & 0.6 & 476.28 \\
\hline
\end{tabular}

Table.6 Growth and Survival of Milk Fish (Chanos chanos)

\begin{tabular}{|c|c|c|c|c|}
\hline $\begin{array}{c}\text { Days of } \\
\text { Culture }\end{array}$ & $\begin{array}{c}\text { Survival } \\
\mathbf{\%}\end{array}$ & ABW (gm) & $\begin{array}{c}\text { ADG } \\
(\mathbf{g m})\end{array}$ & $\begin{array}{c}\text { Biomass } \\
(\mathbf{k g})\end{array}$ \\
\hline 15 & 90 & 20 & 1.3 & 144 \\
\hline 30 & 87 & 28 & 0.93 & 194.88 \\
\hline 45 & 85 & 33 & 0.73 & 224.40 \\
\hline 60 & 82 & 37 & 0.61 & 242.72 \\
\hline 75 & 82 & 51 & 0.68 & 334.56 \\
\hline 90 & 80 & 67 & 0.74 & 428.80 \\
\hline 105 & 77 & 76 & 0.72 & 468.16 \\
\hline 120 & 76 & 88 & 0.73 & 535.04 \\
\hline 135 & 74 & 100 & 0.74 & 592.00 \\
\hline 150 & 72 & 120 & 0.8 & 691.20 \\
\hline 165 & 70 & 136 & 0.82 & 761.60 \\
\hline 180 & 68 & 153 & 0.85 & 832.32 \\
\hline
\end{tabular}


Table.7 Growth and Survival of the Shrimp (P. monodon)

\begin{tabular}{|c|c|c|c|c|}
\hline $\begin{array}{c}\text { Days of } \\
\text { Culture } \\
\text { (DOC) }\end{array}$ & $\begin{array}{c}\text { Survival } \\
\text { \% }\end{array}$ & $\begin{array}{c}\text { ABW } \\
(\mathbf{g m})\end{array}$ & ADG (gm) & $\begin{array}{c}\text { Biomass } \\
(\mathbf{k g})\end{array}$ \\
\hline 40 & 95 & 6.2 & 0.15 & 589.0 \\
\hline 50 & 90 & 8.5 & 0.23 & 765.0 \\
\hline 60 & 90 & 11.7 & 0.32 & 1053.0 \\
\hline 70 & 85 & 14.0 & 0.23 & 1190.0 \\
\hline 80 & 84 & 17.5 & 0.35 & 1470.0 \\
\hline 90 & 82 & 21.2 & 0.35 & 1738.4 \\
\hline 100 & 80 & 24.0 & 0.28 & 1920.0 \\
\hline 110 & 79 & 27.2 & 0.32 & 2148.8 \\
\hline 120 & 75 & 30.2 & 0.30 & 2265.0 \\
\hline 130 & 75 & 34.1 & 0.26 & 2557.5 \\
\hline
\end{tabular}

Table.8 Growth and Survival of the Shrimp (P. monodon) in control experiment 1

\begin{tabular}{|c|c|c|c|c|}
\hline $\begin{array}{c}\text { Days of } \\
\text { Culture } \\
\text { (DOC) }\end{array}$ & $\begin{array}{c}\text { Survival } \\
\text { \% }\end{array}$ & $\begin{array}{c}\text { ABW } \\
(\mathbf{g m})\end{array}$ & $\begin{array}{c}\text { ADG } \\
(\mathbf{g m})\end{array}$ & $\begin{array}{c}\text { Biomass } \\
(\mathbf{k g})\end{array}$ \\
\hline 40 & 85 & 5.9 & 0.14 & 501.5 \\
\hline 50 & 83 & 7.8 & 0.15 & 647.4 \\
\hline 60 & 80 & 10.9 & 0.18 & 872.0 \\
\hline 70 & 75 & 13.8 & 0.19 & 0.35 .0 \\
\hline 80 & 72 & 16.1 & 0.2 & 1159.2 \\
\hline 90 & 69 & 20.2 & 0.22 & 1393.8 \\
\hline 100 & 65 & 23.6 & 0.23 & 1534.0 \\
\hline 110 & 63 & 26.1 & 0.26 & 1644.3 \\
\hline 120 & 60 & 28.2 & 0.23 & 1692.0 \\
\hline 130 & 56 & 30.3 & 0.23 & 1696.5 \\
\hline
\end{tabular}


Table.9 Growth and Survival of the Shrimp (P. monodon) in control experiment 2

\begin{tabular}{|c|c|c|c|c|}
\hline $\begin{array}{c}\text { Days of } \\
\text { Culture } \\
\text { (DOC) }\end{array}$ & $\begin{array}{c}\text { Survival } \\
\text { \% }\end{array}$ & $\begin{array}{c}\text { ABW } \\
(\mathbf{g m})\end{array}$ & $\begin{array}{c}\text { ADG } \\
(\mathbf{g m})\end{array}$ & $\begin{array}{c}\text { Biomass } \\
(\mathbf{k g})\end{array}$ \\
\hline 40 & 80 & 5.6 & 0.14 & 448.0 \\
\hline 50 & 72 & 6.9 & 0.13 & 496.8 \\
\hline 60 & 68 & 9.2 & 0.15 & 625.6 \\
\hline 70 & 65 & 12.6 & 0.18 & 819.0 \\
\hline 80 & 60 & 15.8 & 0.19 & 948.0 \\
\hline 90 & 57 & 18.3 & 0.19 & 1043.1 \\
\hline
\end{tabular}

Fig.1 Range of temperature during fish culture experiment

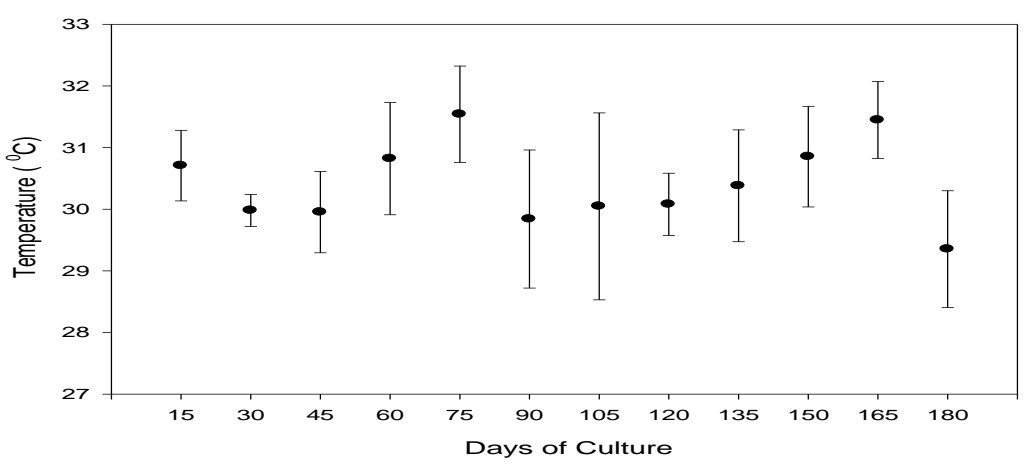

Fig.2 Range of temperature during shrimp culture experiment

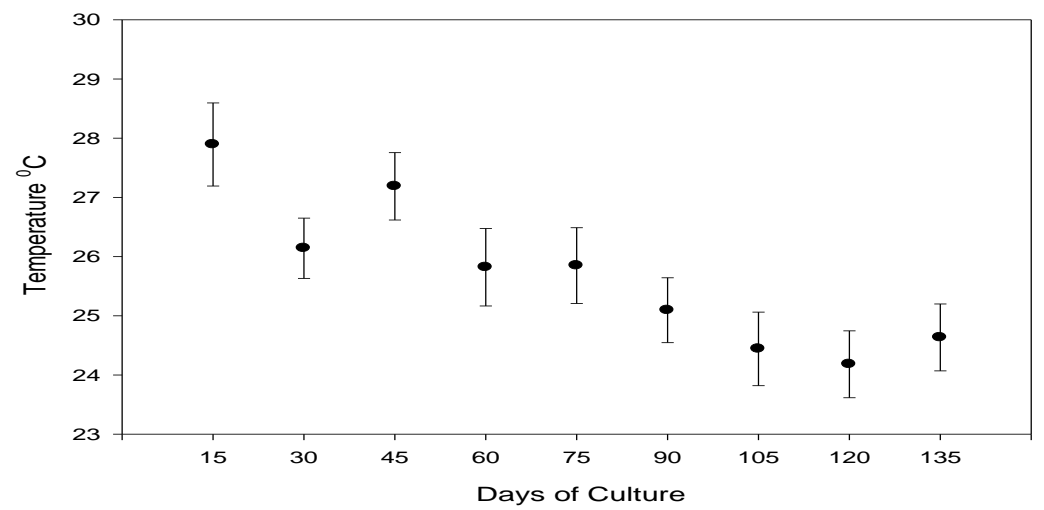


Fig.3 Range of temperature during shrimp culture control experiment 1

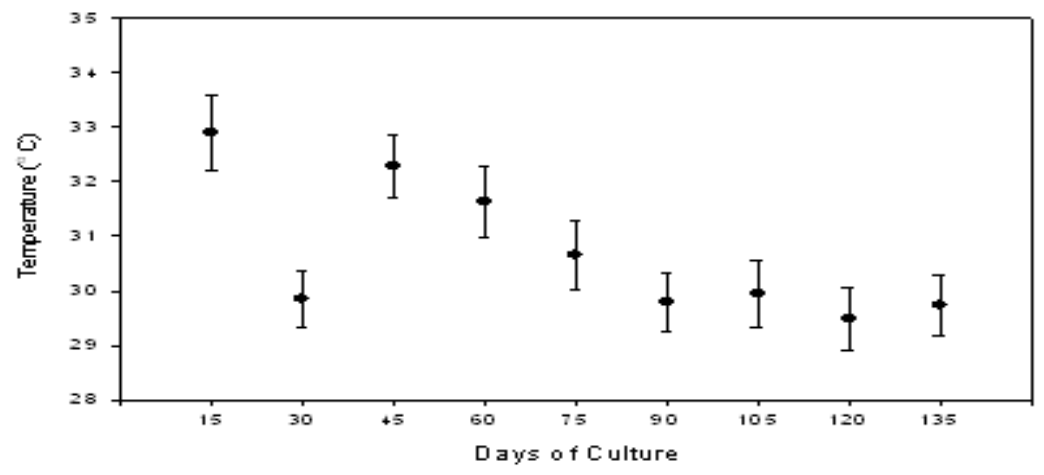

Fig.4 Range of temperature during shrimp culture control experiment 2

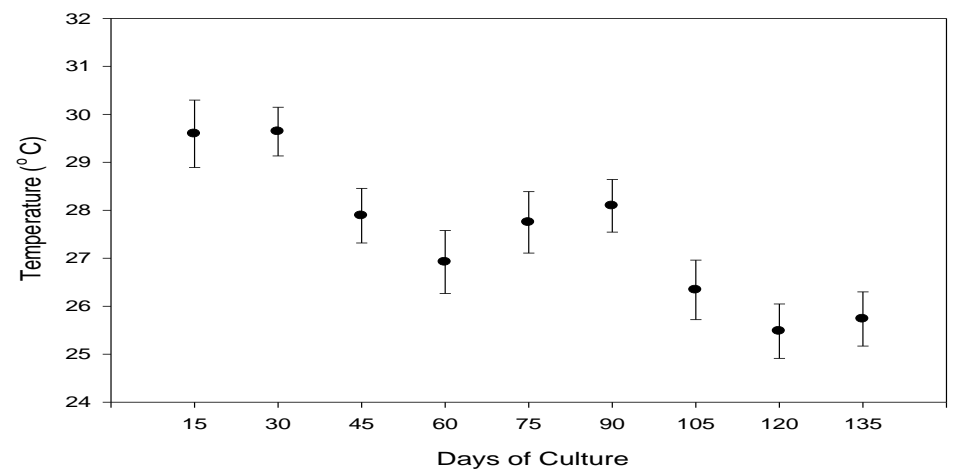

Fig.5 Range of salinity during fish culture experiment

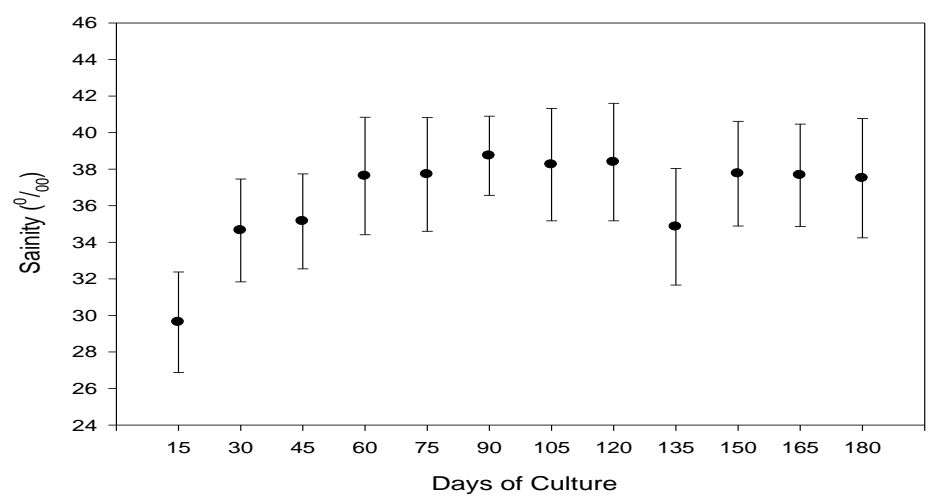


Fig.6 Range of salinity during shrimp culture experiment

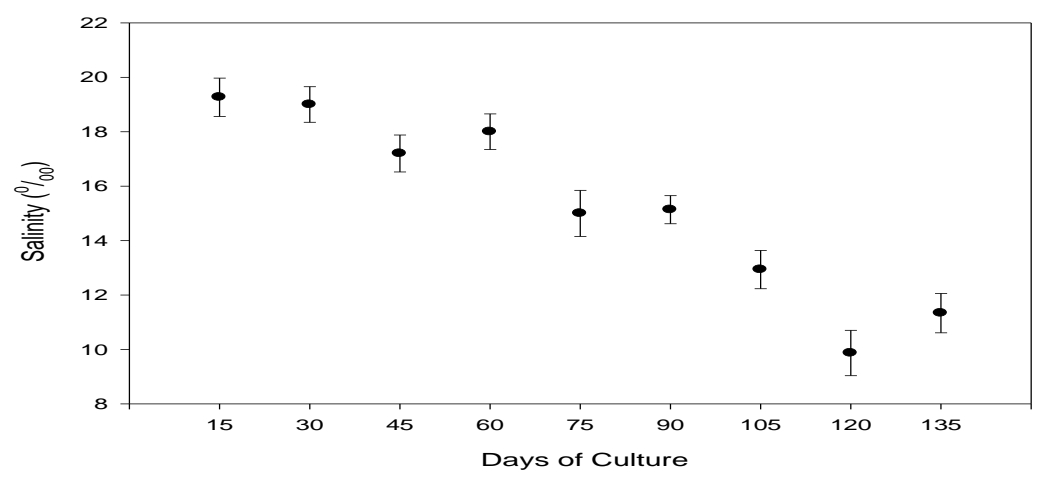

Fig.7 Range of salinity during shrimp culture control experiment 1

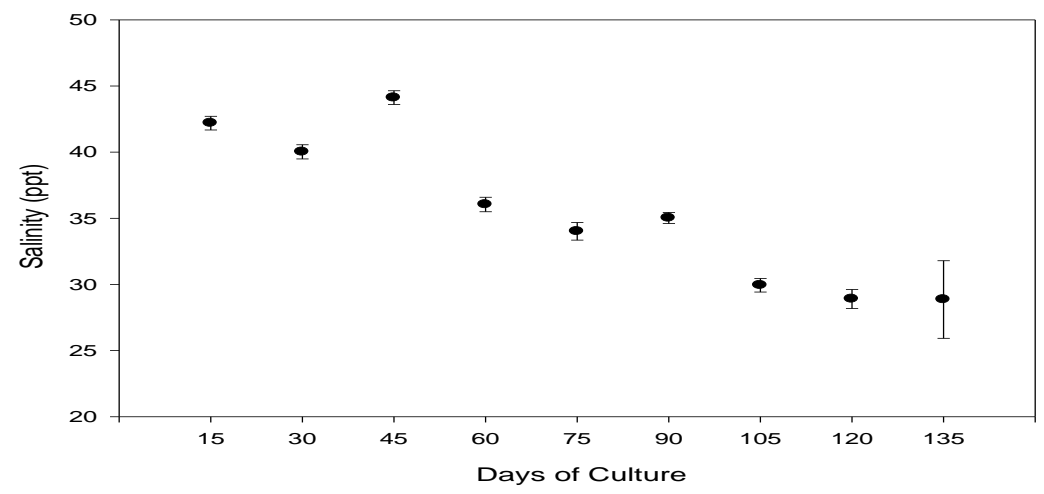

Fig.8 Range of salinity during shrimp culture control experiment 2

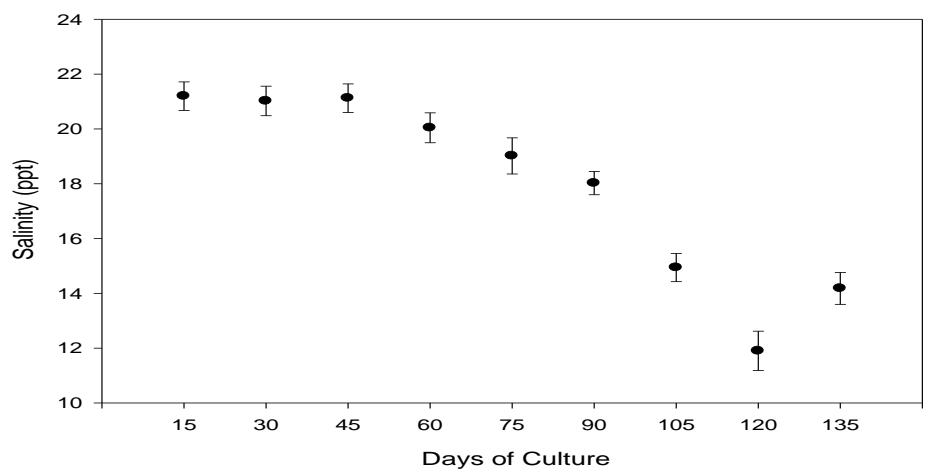


Fig.9 Range of transparency during fish culture experiment

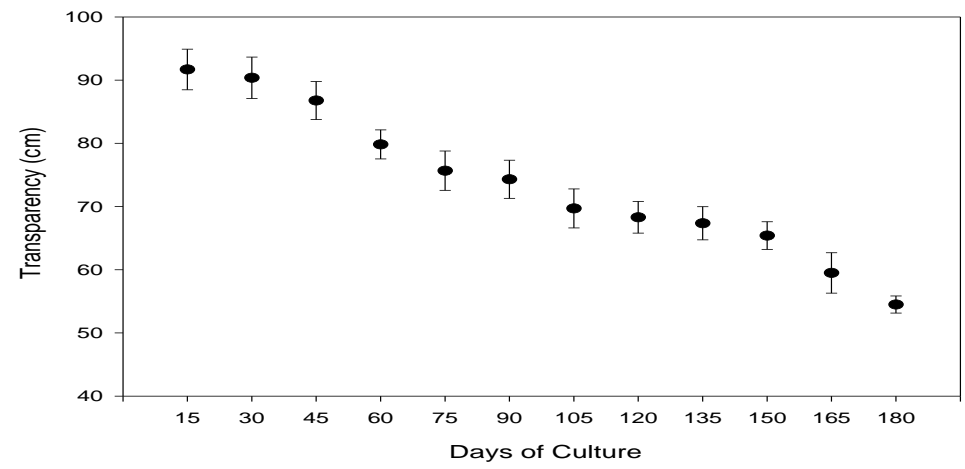

Fig.10 Range of transparency during shrimp culture experiment

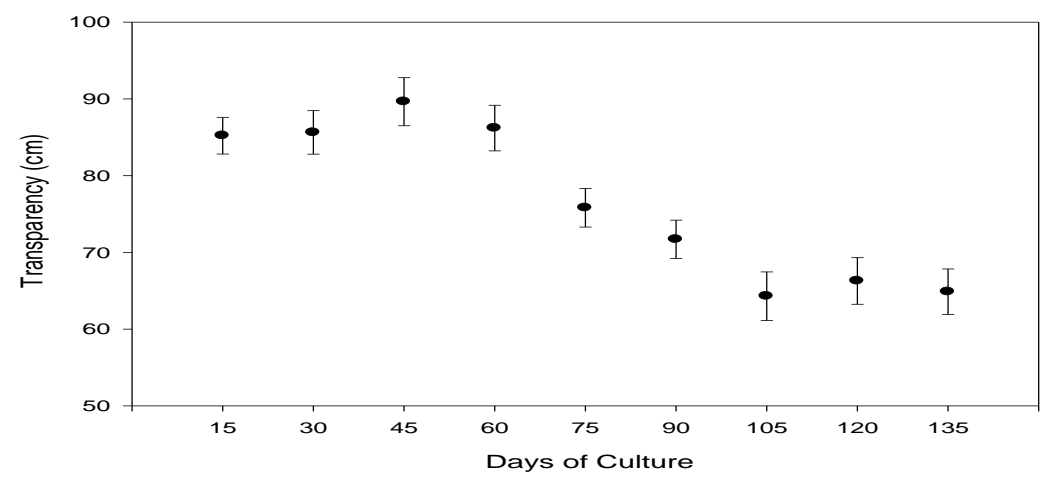

Fig.11 Range of transparency during shrimp culture control experiment 1

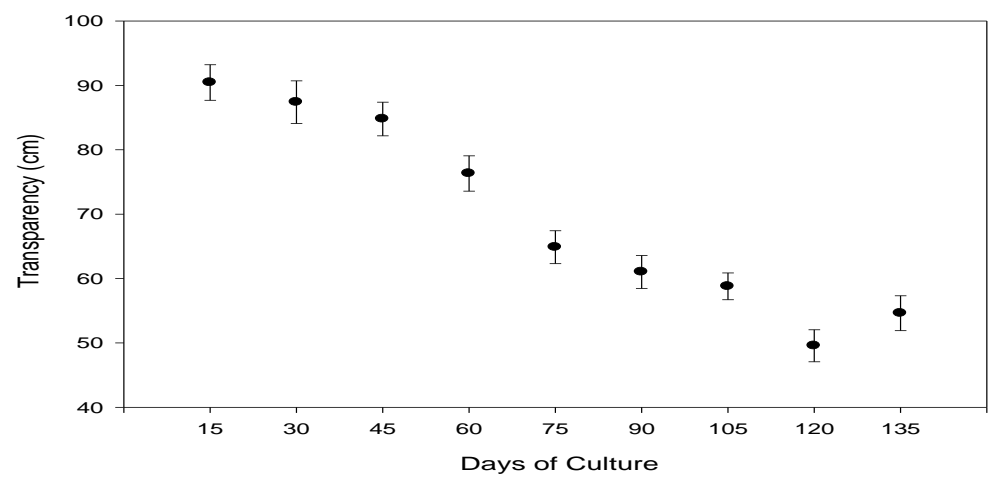


Fig.12 Range of transparency during shrimp culture control experiment 2

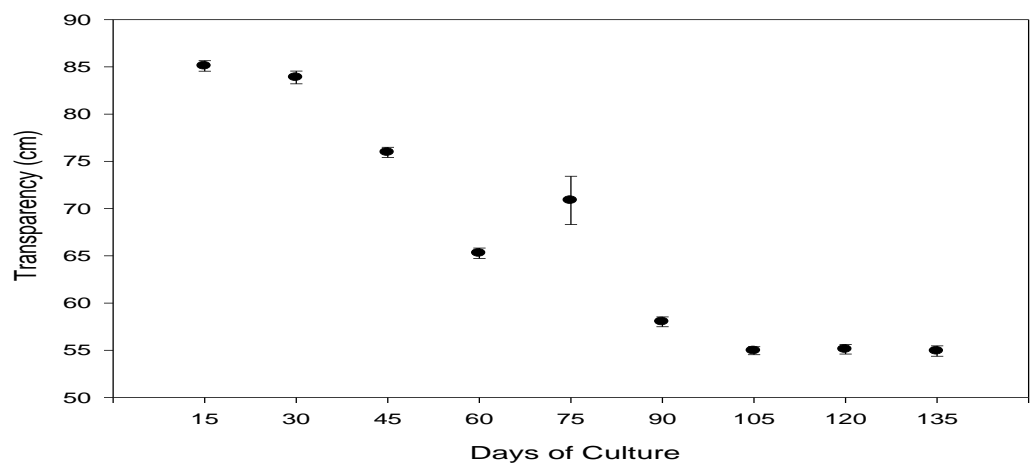

Fig.13 Range of DO during fish culture experiment

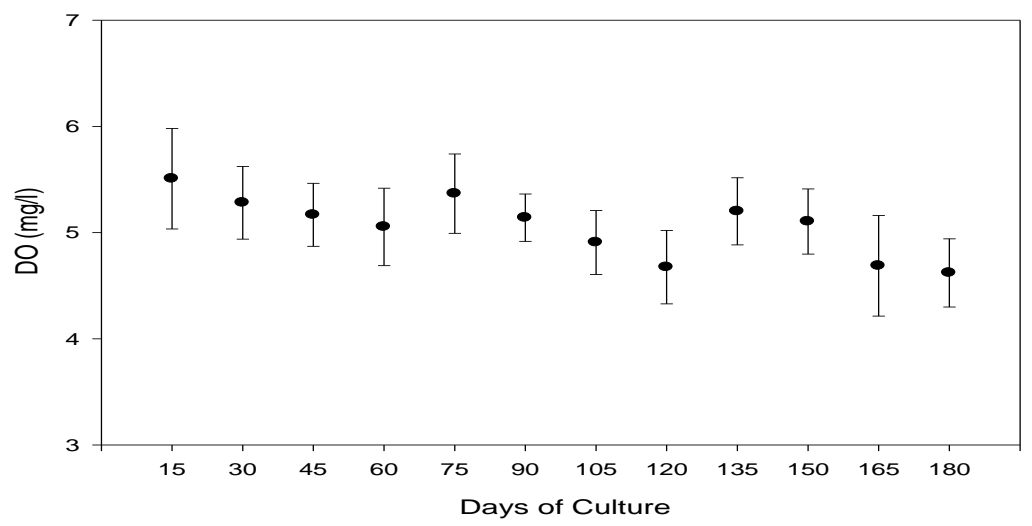

Fig.14 Range of DO during shrimp culture experiment

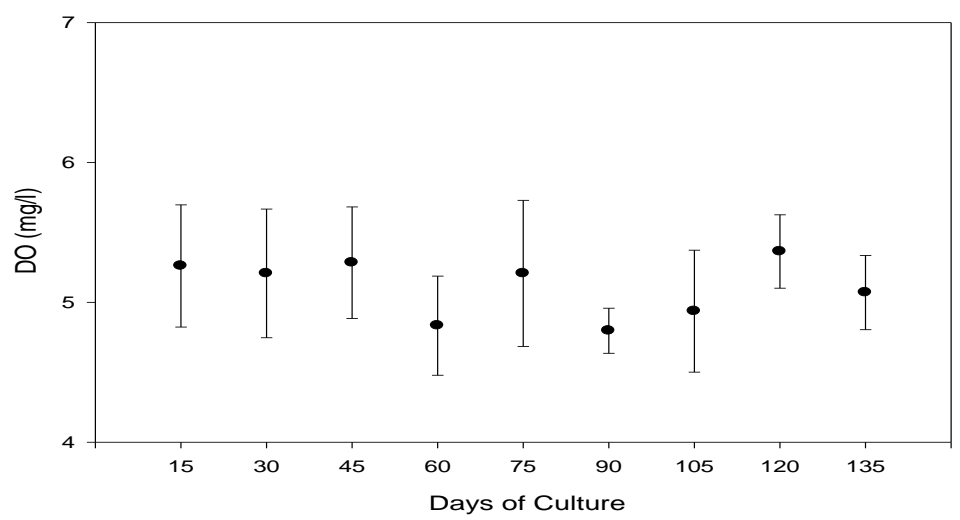


Fig.15 Range of DO during shrimp culture control experiment 1

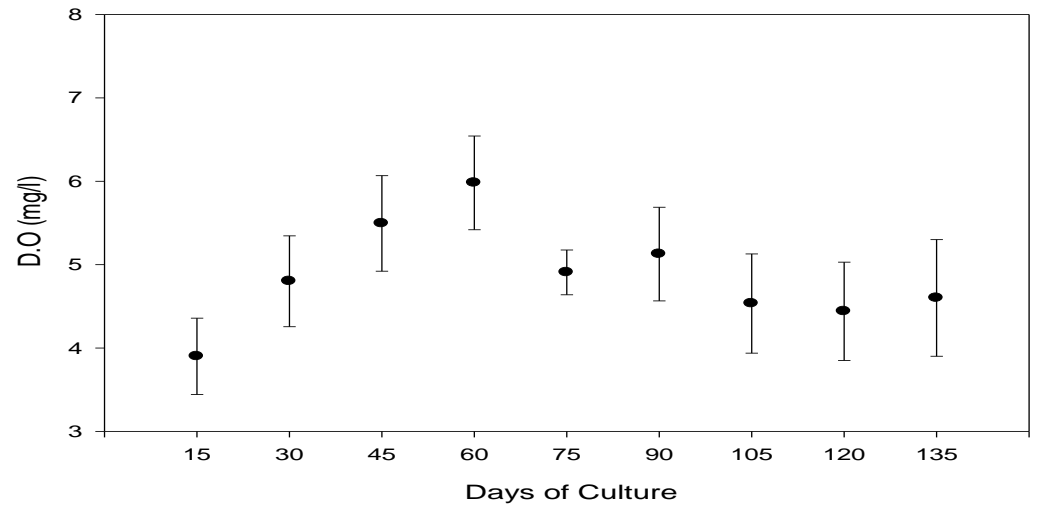

Fig.16 Range of DO during shrimp culture control experiment 2

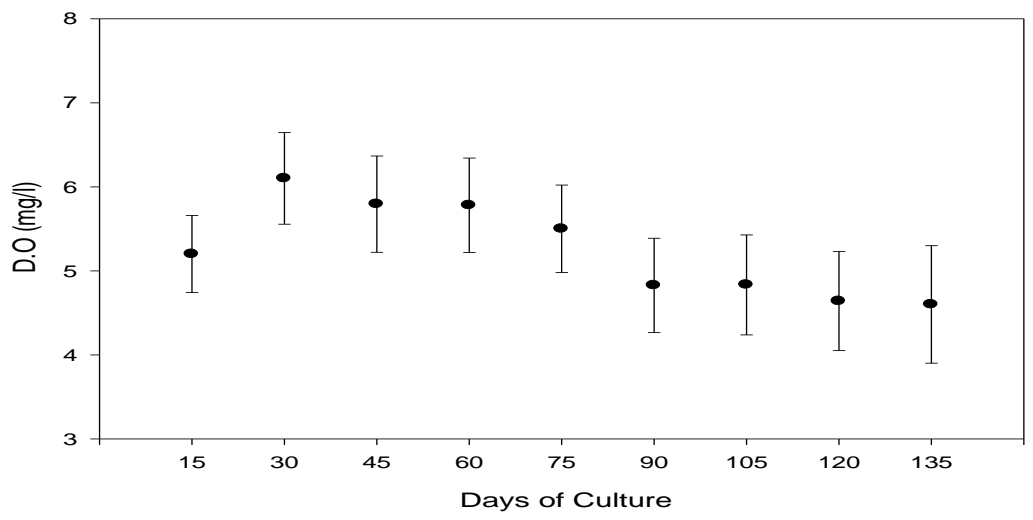

Fig.17 Range of pH during fish culture experiment

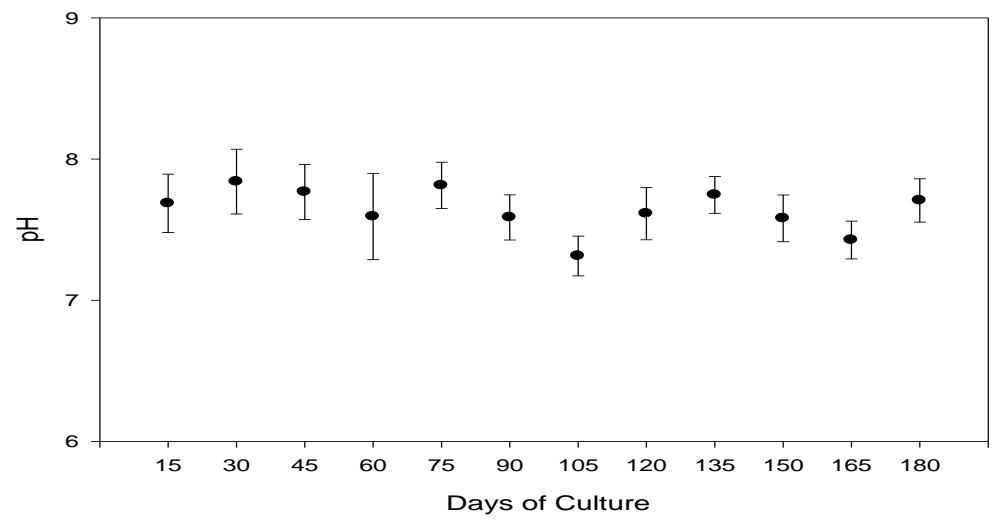


Fig.18 Range of $\mathrm{pH}$ during shrimp culture experiment

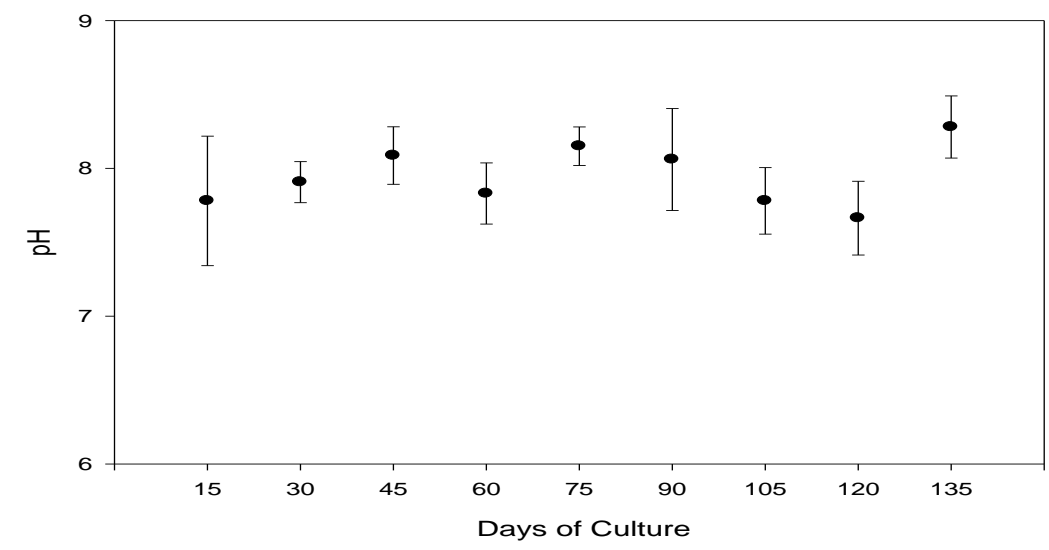

Fig.19 Range of $\mathrm{pH}$ during shrimp culture control experiment 1

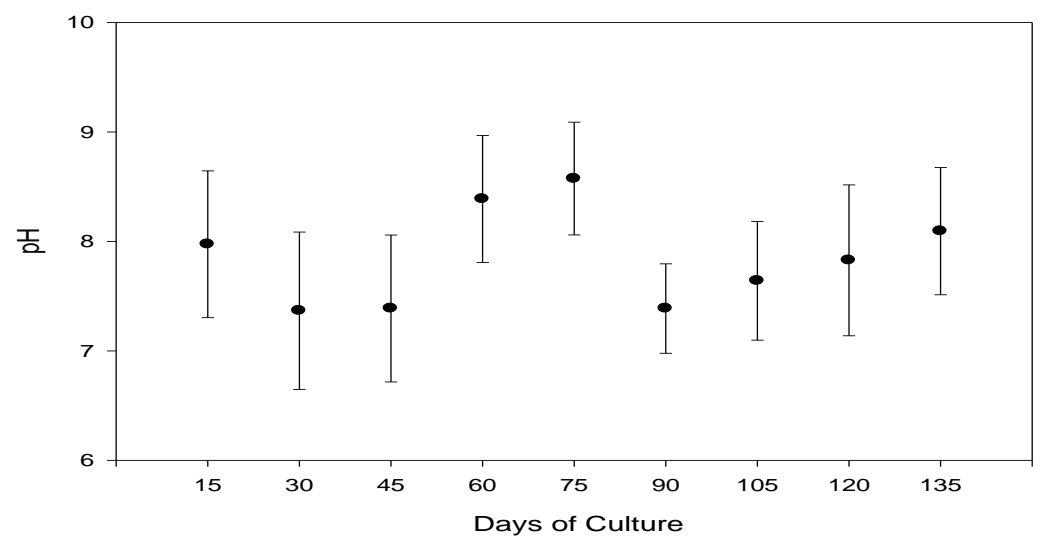

Fig.20 Range of $\mathrm{pH}$ during shrimp culture control experiment 2

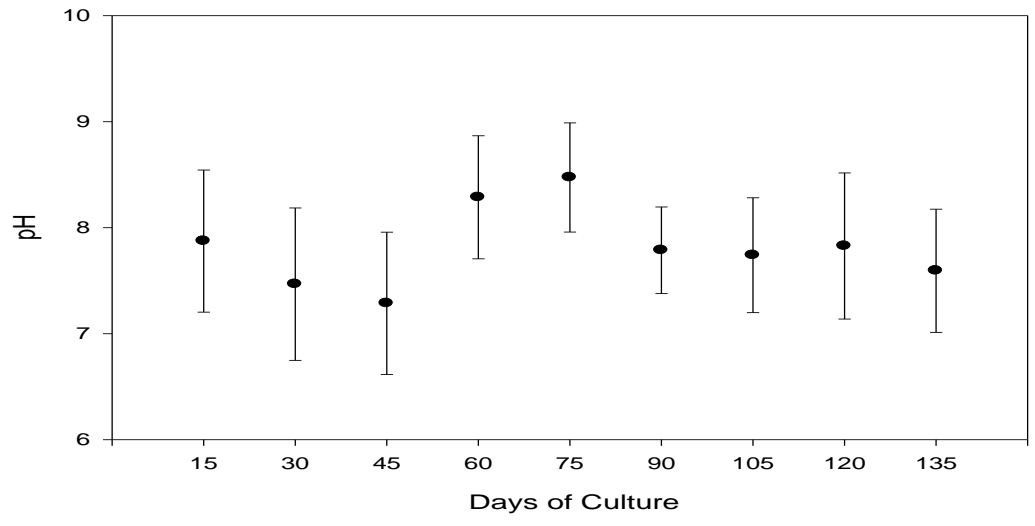


Fig.21 Range of ammonia during fish culture experiment

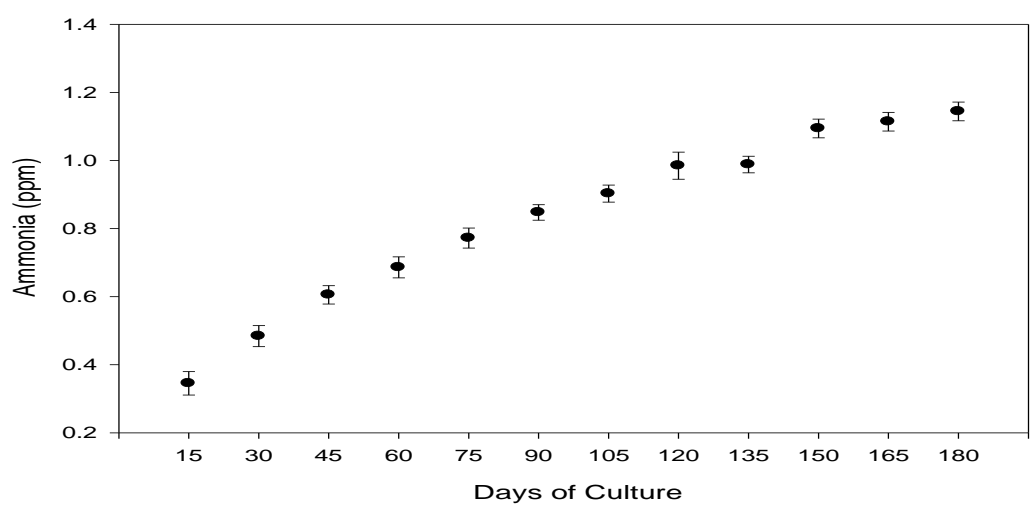

Fig.22 Range of ammonia during shrimp culture experiment

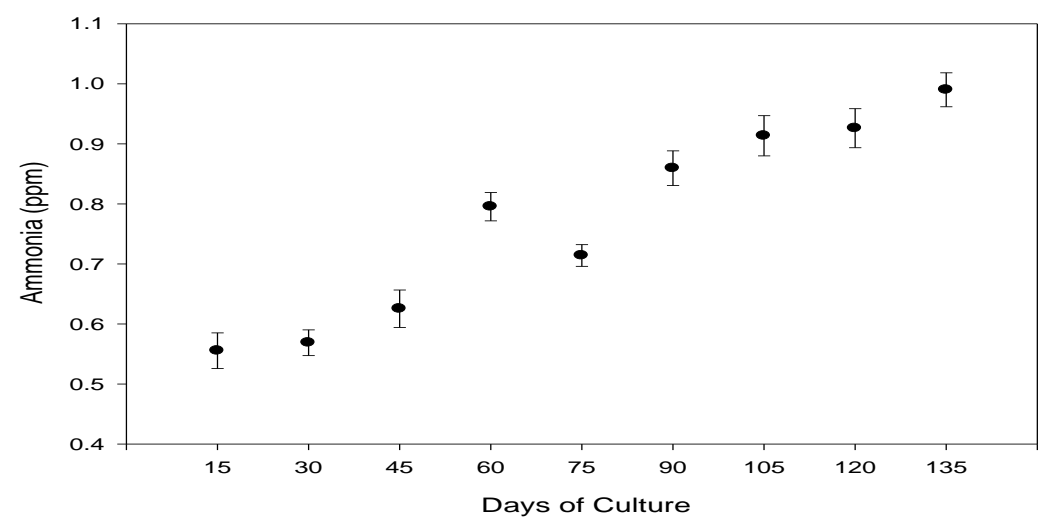

Fig.23 Range of ammonia during shrimp culture control experiment 1

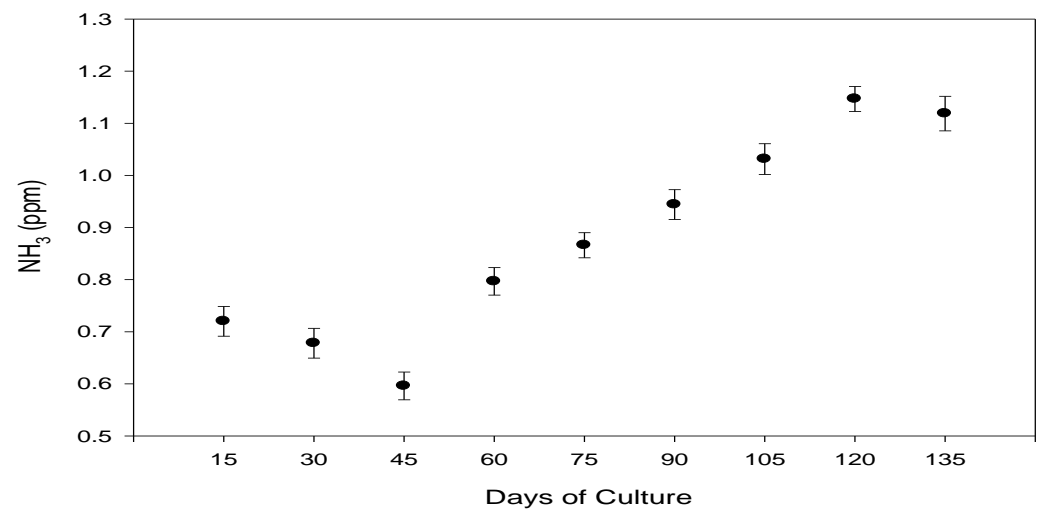


Fig.24 Range of ammonia during shrimp culture control experiment 2

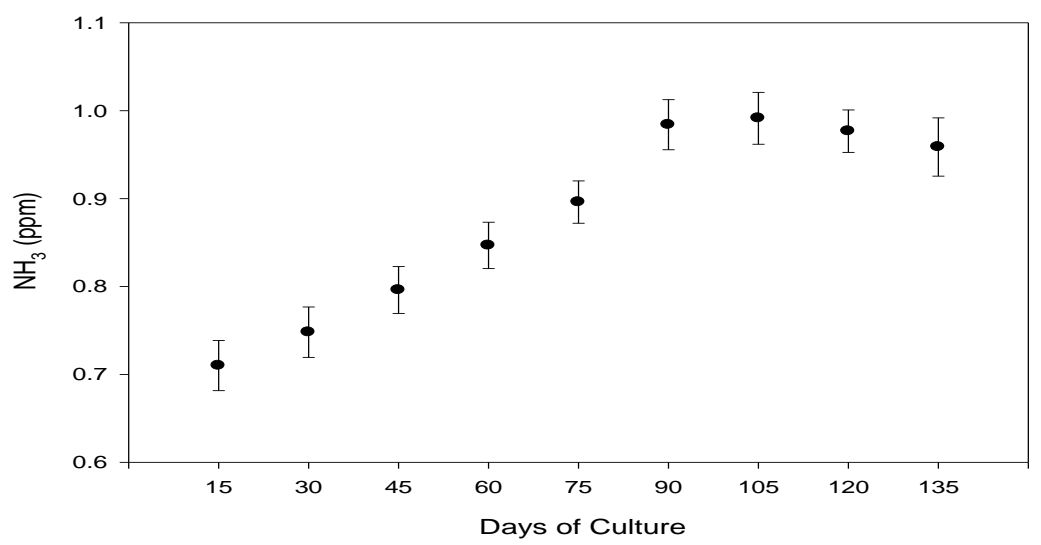

Fig.25 Range of nitrite during fish culture experiment

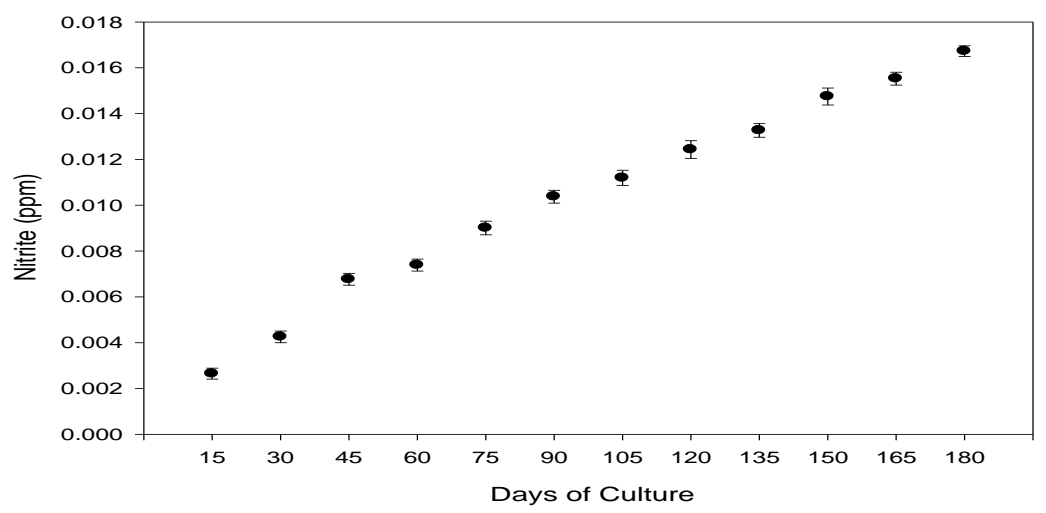

Fig.26 Range of nitrite during shrimp culture experiment

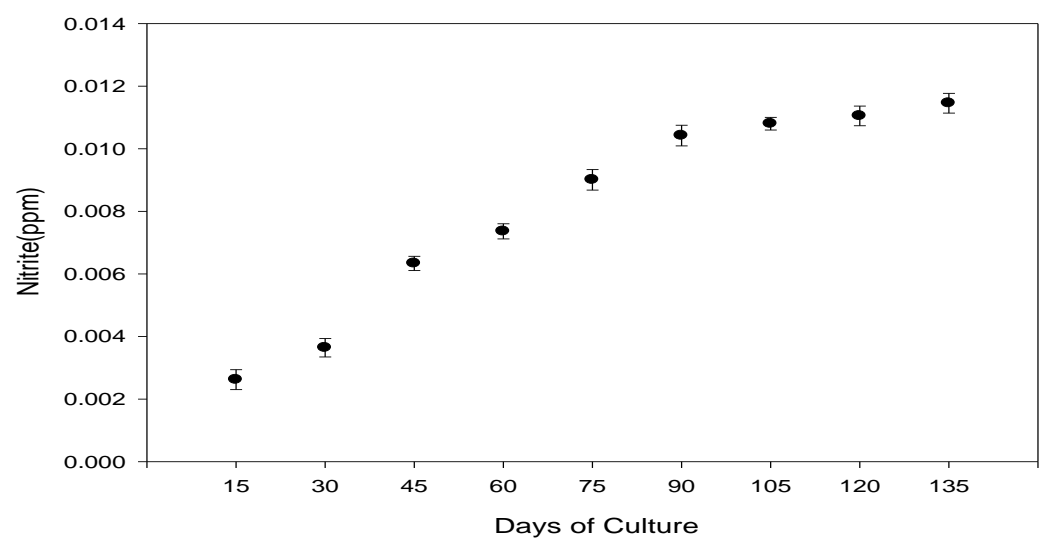


Fig.27 Range of nitrite during shrimp culture control experiment 1

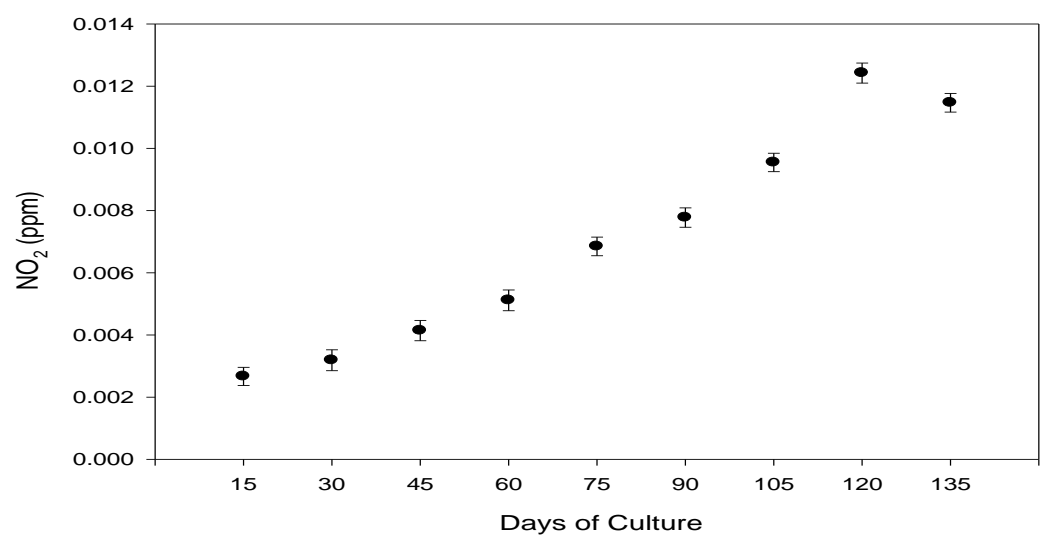

Fig.28 Range of nitrite during shrimp culture control experiment 2

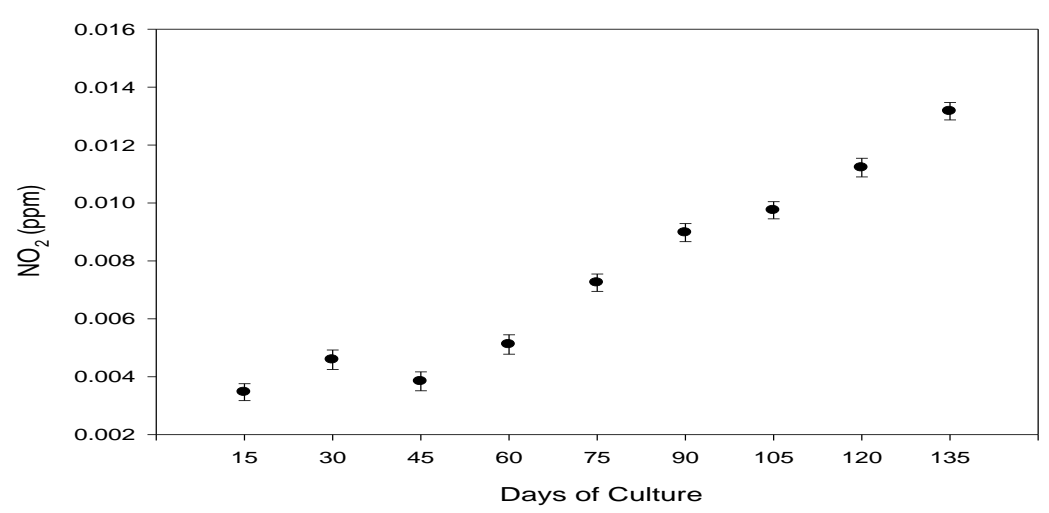

Fig.29 Range of nitrate during fish culture experiment

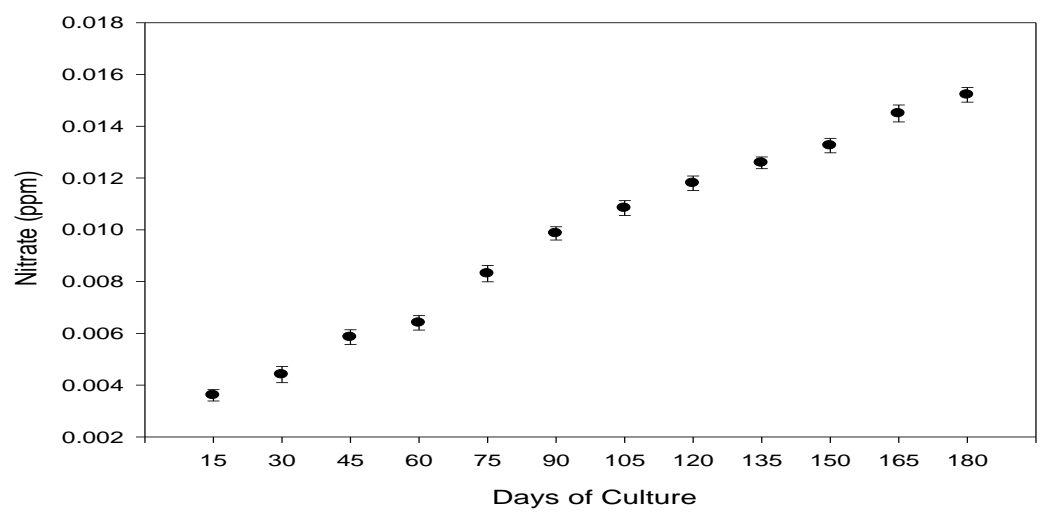


Fig.30 Range of nitrate during shrimp culture experiment

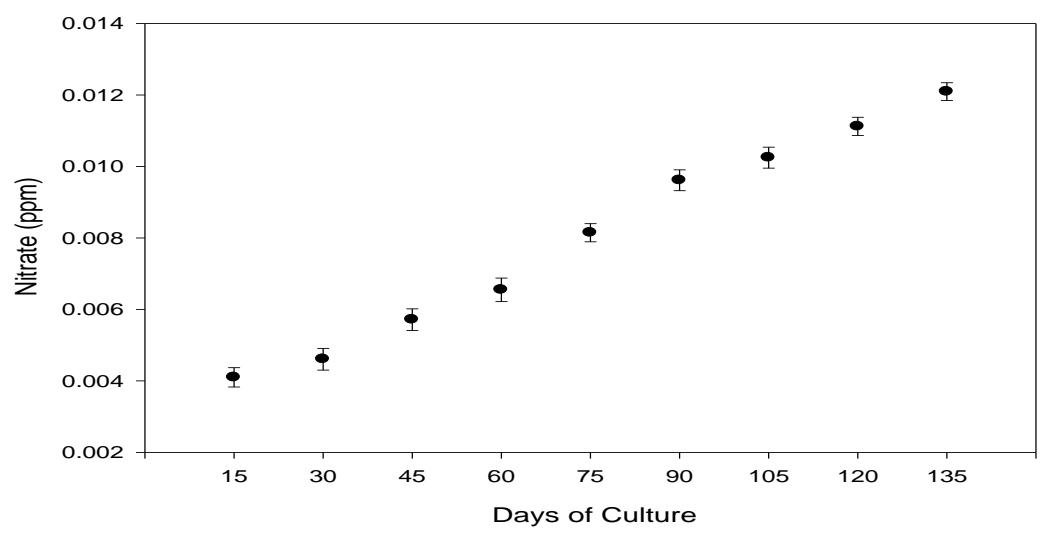

Fig.31Range of nitrate during shrimp culture control experiment 1

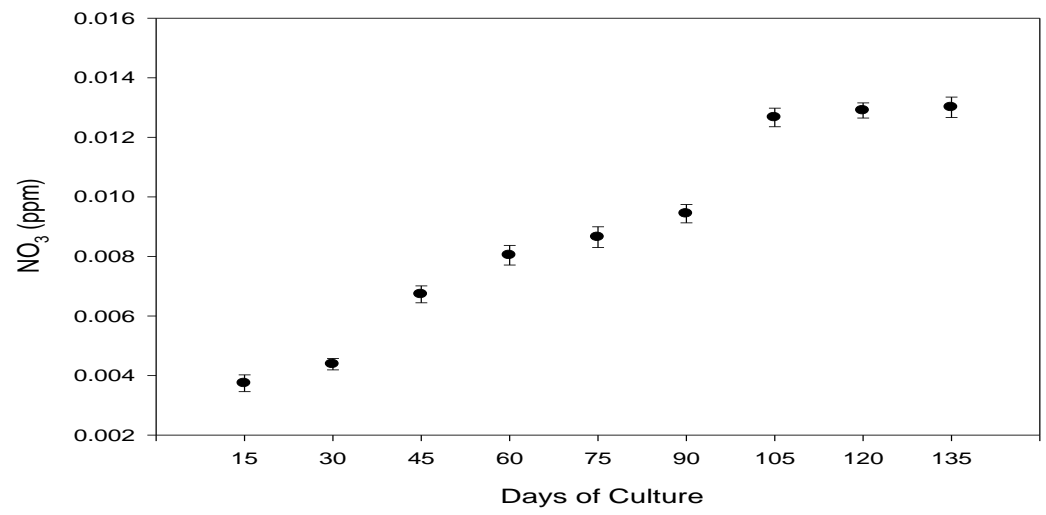

Fig.32 Range of nitrate during shrimp culture control experiment 2

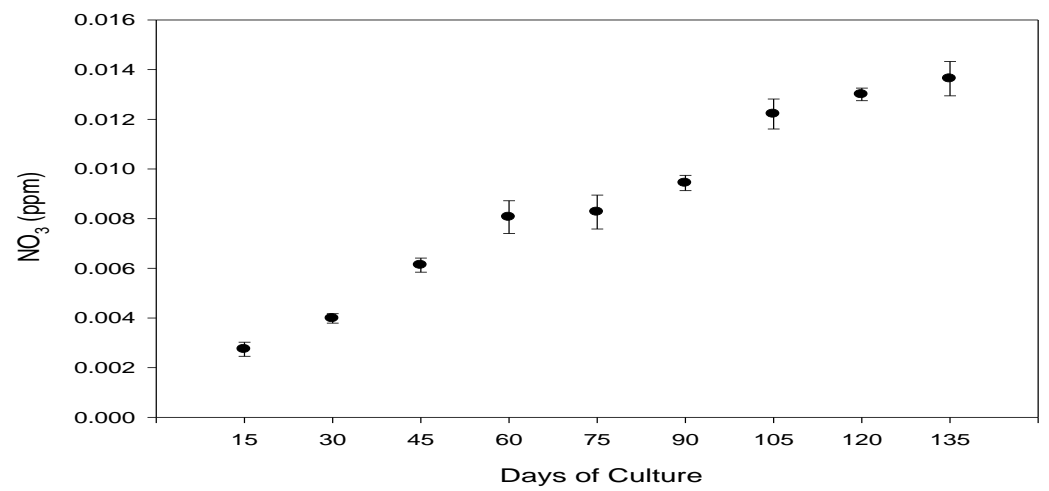


Fig.33 Range of phosphate during fish culture experiment

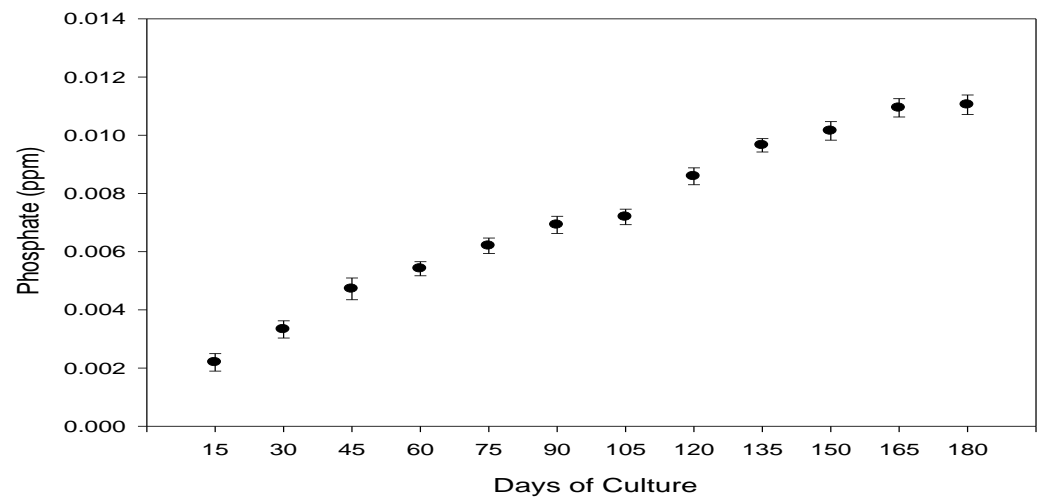

Fig.34 Range of phosphate during shrimp culture experiment

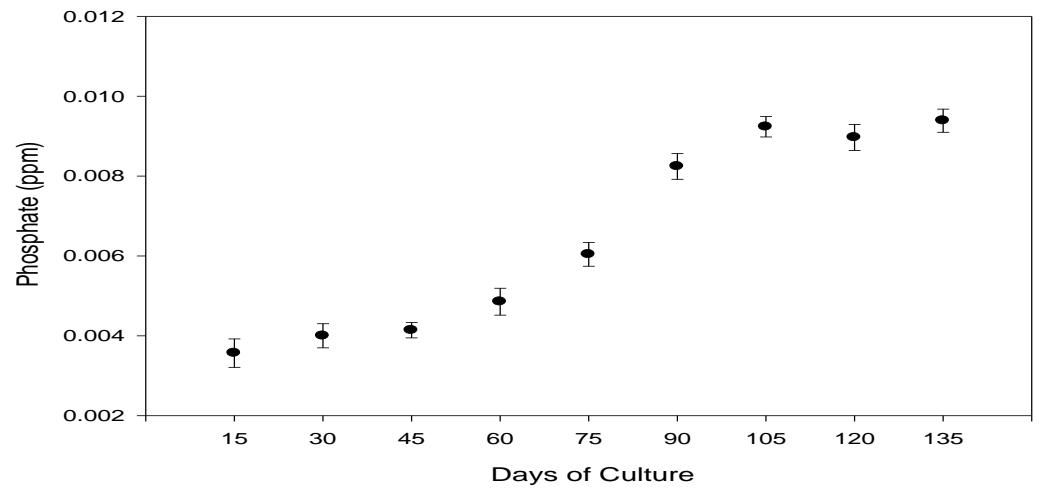

Fig.35 Range of phosphate during shrimp culture control experiment 1

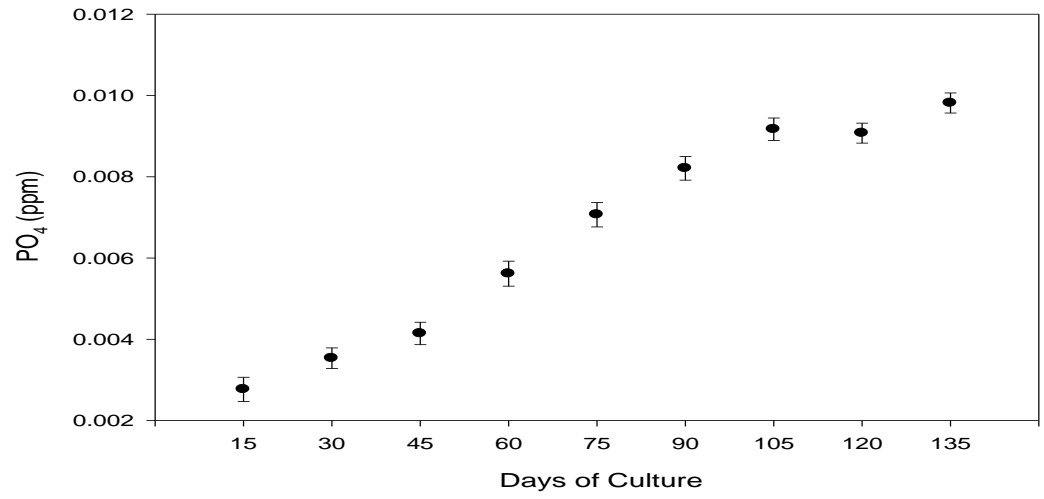


Fig.36 Range of phosphate during shrimp culture control experiment 2

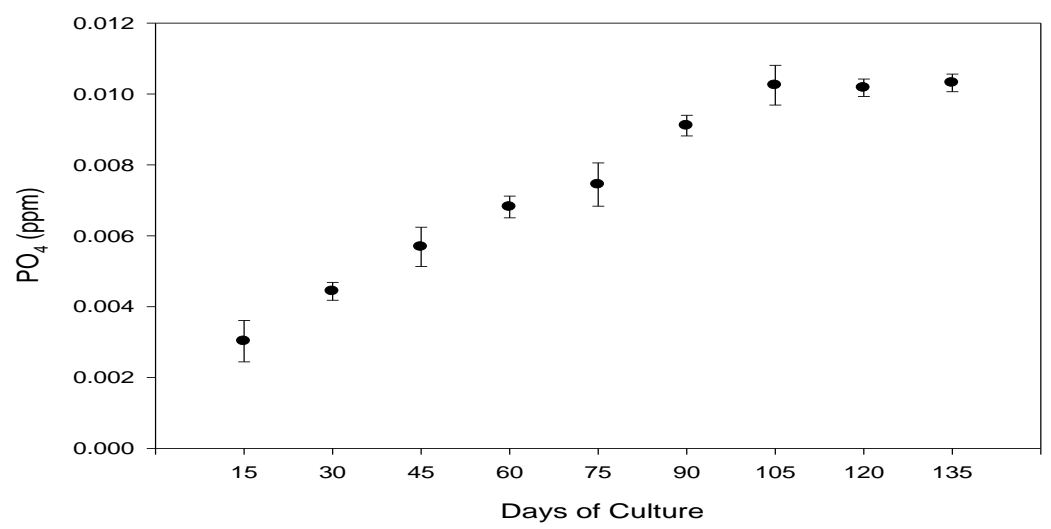

Fig.37 Range of silicate during fish culture experiment

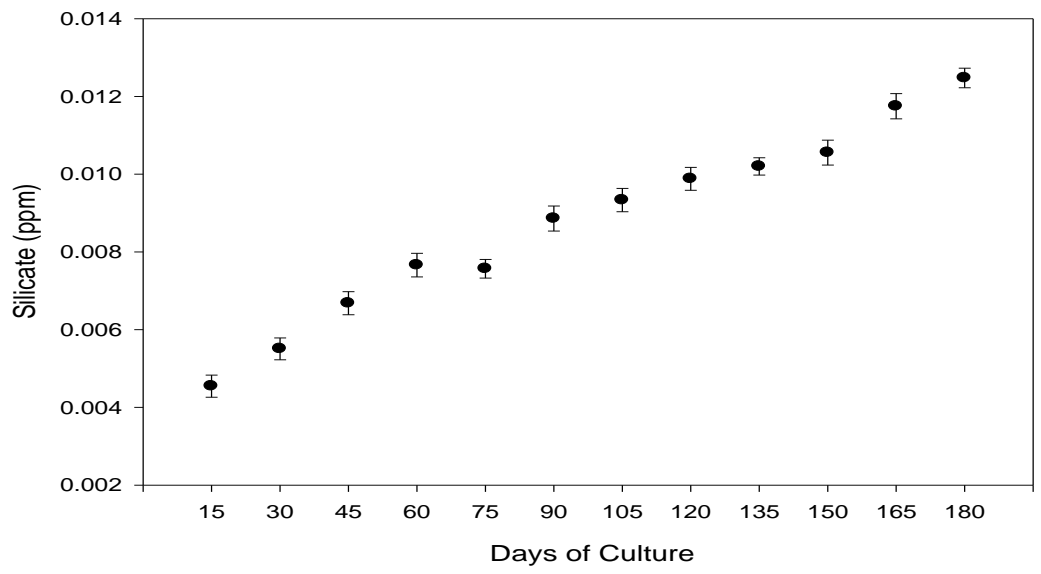

Fig.38 Range of silicate during shrimp culture experiment

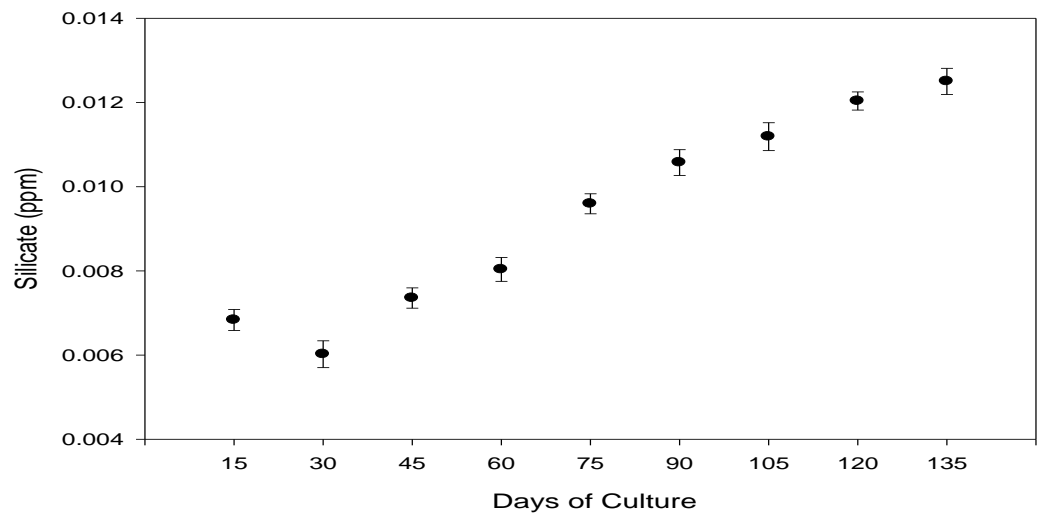


Fig.39 Range of silicate during shrimp culture control experiment 1

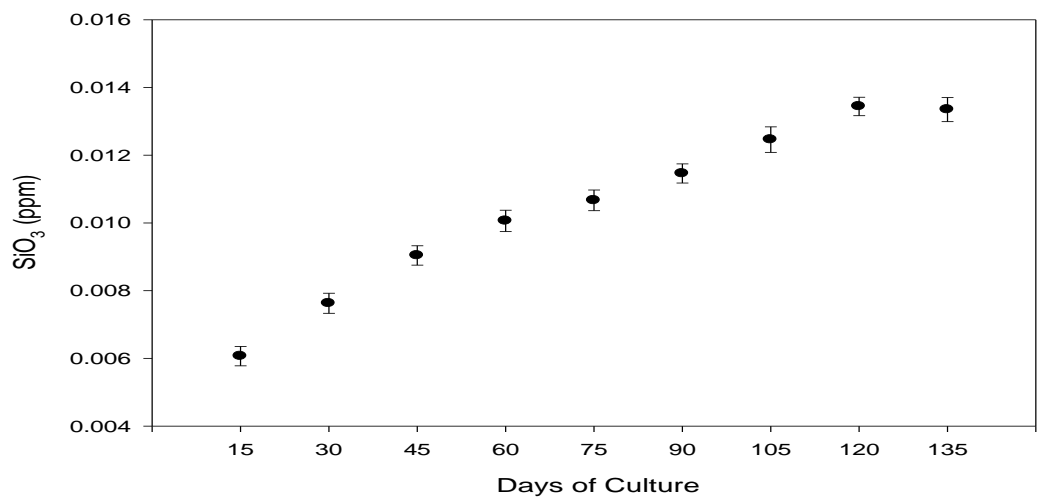

Fig.40 Range of silicate during shrimp culture control experiment 2

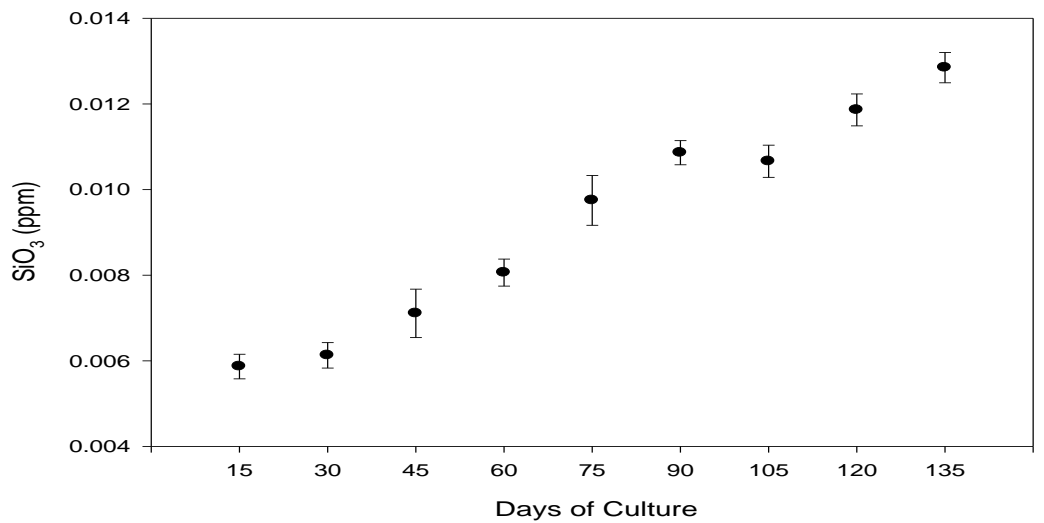

Plate II

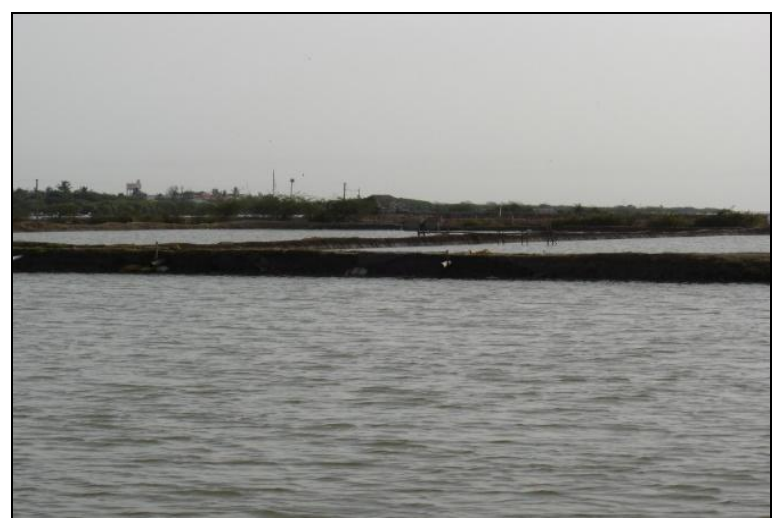

View of the Experimental ponds

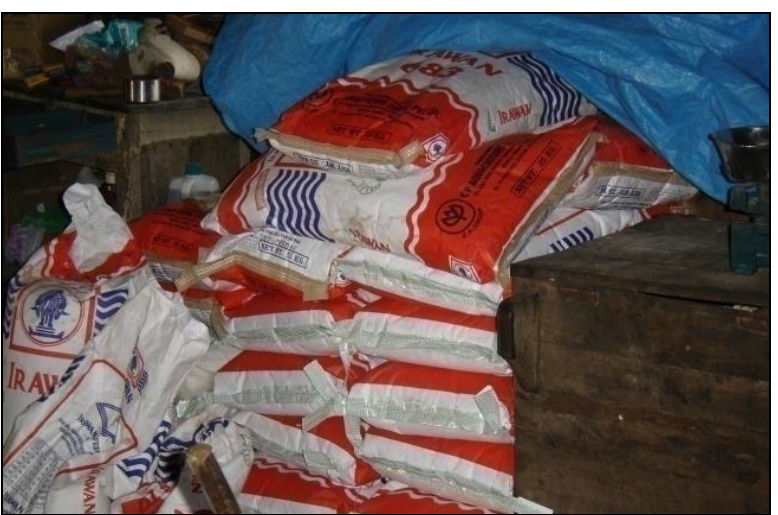

Shrimp feed used 


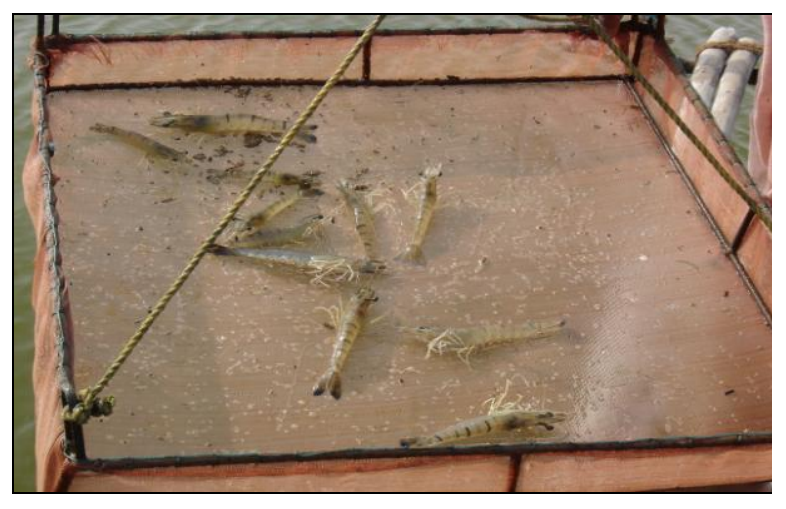

Plate II

View of shrimps in the check tray

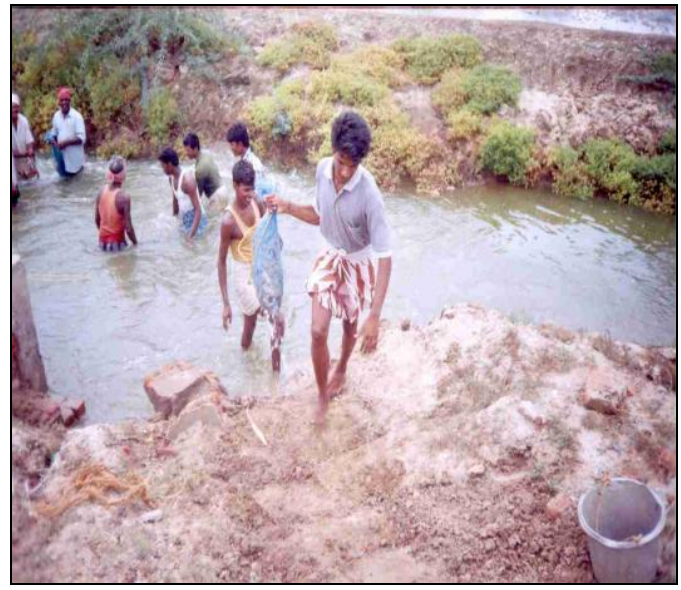

Harvesting of shrimps

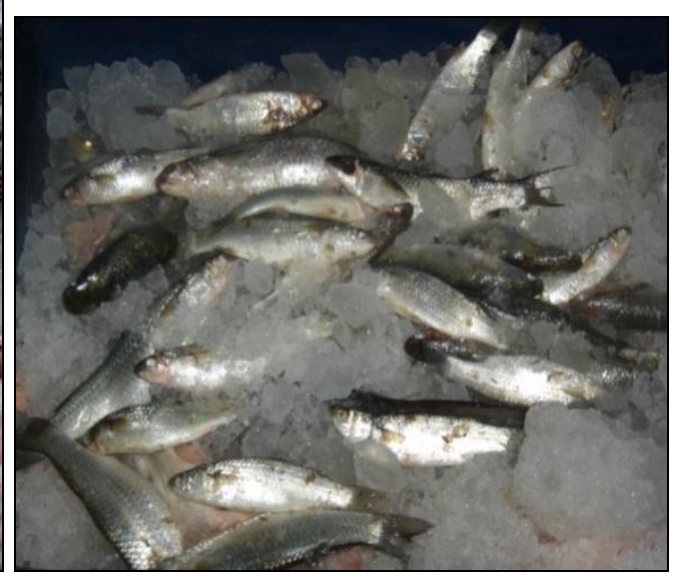

Harvested mullets

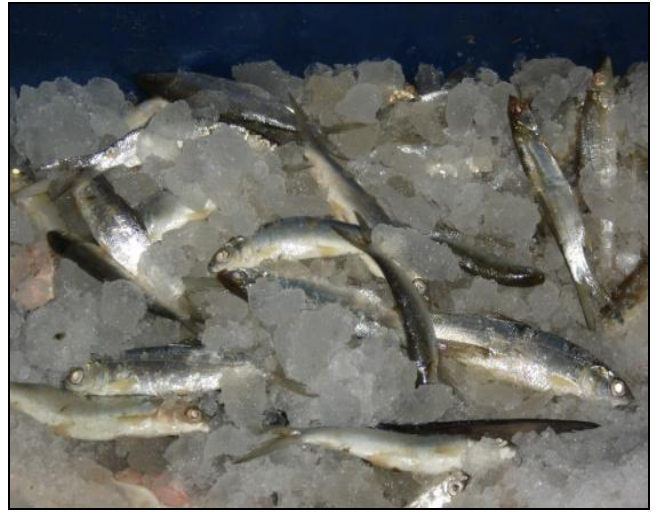

Harvested milk fishes

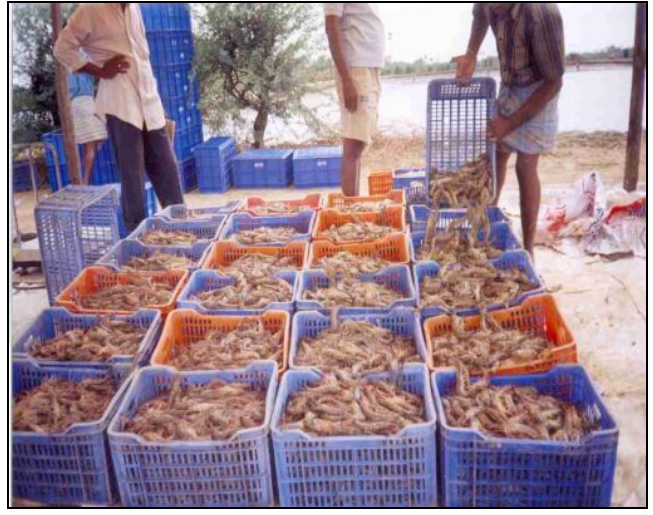

Harvested shrimps 


\section{Water quality parameters}

In shrimp culture, the water quality can be defined as the suitability of water for the survival, growth and production of shrimps. Hence to ensure a good water quality, the water quality parameters were monitored and accordingly, regular water exchange was done during the present experiment.

The water temperature is a major environmental factor that affects the growth and survival of any aquatic organism. In the present fish culture experiment, the water temperature of 28.5 to $32.4{ }^{\circ} \mathrm{C}$ had no harmful effect. In the case of warm water fishes the maximum metabolic activity was seen at 30 to $35^{\circ} \mathrm{C}$ (Beamish and Dickie, 1967; Fry and Hart, 1984). In the light of this, temperature was favourable for the stocks in the pond with minor variations between unit times.

In the present experiment, the $\mathrm{pH}$ varied from 7.2 to 8.1 , which had positive effect on the activity of the fishes, as also reported by Huet (1975) who observed that the $\mathrm{pH}$ range of 7.0 to 8.0 (neutral or slightly alkaline) is best for fish culture. The present finding is in close agreement with those of Huet (1975).

The master environmental factor of salinity, during the experiment was ranging from 26 to 42 ppt. In spite of salinity values higher than $35 \mathrm{ppt}$ in certain occasions, there was no adverse effect since the mullets and milkfishes can tolerate wide range of salinities as euryhaline species (Bardach et al., 1972). The food intake, growth rate, food conversion and protein synthesis have been found to be affected by ambient oxygen level (Medale, 1985). In the present study, the dissolved oxygen values were fluctuated from 4.1 to $6.2 \mathrm{mg} / \mathrm{l}$, the needs of the stocked stocks in the ponds without any stress for want of dissolved oxygen.
The microbial analysis during the present study indicates that there was an increase in the population of sucrose positive bacteria, mainly Vibrio, during the fish culture experiment, which may be attributed to the addition of carbon rich diets, such as rice bran and groundnut oil cake and in the case of the shrimp culture experiment, the populations of sucrose negative bacteria increased. In the experimental pond 2 , the pathogenicity of sucrose negative strains went to the extent of termination of the experiment. Paclibare et al., (1998) stated that $V$. harveyi have two major biotopes, namely the sucrose positive and sucrose negative forms. Most of the pathogenic strains of $V$. harveyi of shrimp are sucrose negative while the sucrose positive strains are benign and even used as probiotics (Owens et al., 1996). Paclibare et al., (1998) observed that the sucrose positive Vibriosis usually dominate ponds of healthy tilapia and also noted that, crop rotation of shrimps and tilapia reduces disease incidence in shrimp culture. The greater phylogenetic differences between the cultured organisms used in crop rotation, the better sanitary effects have been experimented (Francis and Clegg, 1990). In this experiment, the shrimp crop rotated with mullets and milkfishes, which belong to different orders within the animal kingdom, resulted in rewarding crop, in the same culture system.

The performance of shrimp in experimental pond, after the crop of fish culture, was remarkably good. While comparing the performance of shrimps in the experiment pond and control pond, experimental shrimp pond yield was interesting with $695.3 \mathrm{~kg}$ of more production, similarly survival rate was $25 \%$ higher, $\mathrm{ABW}$ was $2.9 \mathrm{~g}$ higher and ADG was $0.16 \mathrm{gm}$ higher for 90 days of culture. These results clearly establish the advantages of crop rotation with fish than continuous culture of shrimps in the same system. Further, it is to be stressed that in the 
experimental pond, shrimp culture was possible upto 130 days due to previous fish culture, while, the shrimp crop could not continue beyond 90 days in the continuous shrimp culture pond due to severe bacterial disease and mortality.

\section{References}

Bardach, J.E., J.H. Ryther and W.O. Mc Larney, 1972. Aquaculture: the farming and husbandry of fresh water and marine organisms. Wiley-Interscience, New York.

Beamish, F.W.H. and L.M. Dickie, 1967. Metabolism and biological bases of fresh water fish production. Oxford, Blackwell Sci., Publ., 215-242.

Berger, R.D., 1977. Application epidemiological principles to achieve plant disease control. Ann. Rev. Phytopath., 15: 165-183.

Francis, C.A. and M.D. Clegg, 1990. Crop rotations in sustainable production systems. In: Sustainable Agricultural Systems. Soil and Water Conservation Society, Lowa, 696 pp.

Fry, E.J. and J.L. Hart, 1984. The relation of temperature to oxygen consumption in the gold fish. Biol. Bull., 94: 63-73.

Huet, M., 1975. Text book of fish culture. Fishing News Books Ltd., England. $5436 \mathrm{pp}$.

Jiravanichpaisal, P.T., T. Miyazaki and C. Limsuwan, 1994. Histopathology, biochemistry and pathogenicity of Vibrio harveyi infecting black tiger prawn Penaeus monodon. J. Aquat. Anim. Health, 6: 27-35.
Karunasagar, I., S.K. Otta and I. Karunasagar, 1996. Effect of chlorination on shrimp pathogenic Vibrio harveyi. Book of Abstracts, World Aquacult, 1996, Thailand.

Kommendahl, T. and L.A. Todd, 1991. The environmental control of plant pathogens using eradication. In: Piementel, D. (ed.), CRC Handbook of Pest Management in Agriculture. CRC Press, Boca Raton, Florida.

Liu, P.C., K.K. Lee and S.N. Chen, 1996. Pathogenicity of different isolates of Vibrio harveyi in tiger prawn Penaeus monodon. Lett. Appl. Microbiol., 22(6): 413-416.

Medale, A.J., 1985. Influence d'une reduction du taux d' oxygene del' eau pendant une periode prolongee, Sur certains aspects du metabolism azote chez la truite arc-en-ciel (Salmo gairdneri Rich). These 3 eme cycle univ. Paul sabatier. Touluse, France.

Owens, L., D.A. Austin and B. Austin, 1996. Effect of strain origin on siderophone production in Vibrio harveyi isolates. Dis. Aquat. Org., 27: 157-160.

Paclibare, J.O., M.C.J. Verdegem, W.B. Van Muiswinkel and B.L.A. Heisman, 1998. The potential for crop rotation in controlling diseases in shrimp culture. Naga, the ICLARM Quarterly.

Reeves, T.G., A. Ellington and H.D. Brooke, 1984. Effects of lupin wheat rotations on soil fertility, crop disease and crop yields. Aust. J. Agric. Anim. Husb., 24: 595-600.

\section{How to cite this article:}

Santhi, N., and Deivasigamani, B. 2017. Crop Rotation as a Better Sanitary Practice in Culture of Penaeus monodon (Fabricius, 1798). Int.J.Curr.Microbiol.App.Sci. 6(2): 1418-1443. doi: http://dx.doi.org/10.20546/ijcmas.2017.602.160 